\title{
Acoustic emission characterization of sliding wear under condition of direct and inverse transformations in low- temperature degradation aged $\mathrm{Y}-\mathrm{TZP}$ and $\mathrm{Y}-\mathrm{TZP}-\mathrm{AL}_{2} \mathrm{O}_{3}$
}

\author{
Nikolai L SAVCHENKO ${ }^{1, *}$, Andrey V FILIPPOV ${ }^{1,2}$, Sergei Yu TARASOV ${ }^{1,2}$, Andrey I DMITRIEV ${ }^{1,3}$, \\ Evgeny V SHILKO ${ }^{1,3}$, Aleksandr S GRIGORIEV ${ }^{1}$ \\ ${ }^{1}$ Institute of Strength Physics and Materials Science SB RAS, Tomsk 634055, Russian Federation \\ ${ }^{2}$ National Research Tomsk Polytechnic University, Tomsk 634050, Russian Federation \\ ${ }^{3}$ National Research Tomsk State University, Tomsk 634050, Russian Federation \\ Received: 05 April 2018 / Revised: 24 May 2018 / Accepted: 14 June 2018 \\ (C) The author(s) 2018. This article is published with open access at Springerlink.com
}

\begin{abstract}
In this research, results of the investigation of the sliding friction and wear of yttria-stabilized tetragonal zirconia polycrystalline (Y-TZP) and $\mathrm{Y}-\mathrm{TZP}-\mathrm{Al}_{2} \mathrm{O}_{3}$ samples preliminarily subjected to low-temperature degradation are reported. The investigation was carried out using a pin-on-disk tribometer with simultaneous recording of acoustic emission (AE) and vibration acceleration. The sliding wear process was found to be determined by dynamic direct and inverse Y-TZP transformations detected by monoclinic and tetragonal X-ray diffraction peak ratios. The AE signals generated under direct and inverse transformations can be used to characterize wear and friction mechanisms as well as direct and inversed sliding-induced phase transformations. The AE signal energy grows with the friction coefficient and the inverse transformation degree. Reduction of the AE signal energy indicates establishing the mild wear stage caused by effective stress-induced direct martensitic transformation. The AE signal median frequency increases in the case of lower friction. Numerical studies of wear subsurface fracture under conditions of stress-induced martensitic transformation were used to elucidate the role played by the phase transformation in $\mathrm{Y}$-TZP and $\mathrm{Y}-\mathrm{TZP}-\mathrm{Al}_{2} \mathrm{O}_{3}$. Martensitic transformation in Y-TZP was described with use of the non-associated dilatant plasticity model. Simulation results particularly show that increase in the value of dilatancy coefficient from 0 to 0.2 is accompanied by $25 \%-30 \%$ reduce in characteristic length and penetration depth of sliding-induced subsurface cracks. As shown the AE may be an effective tool for in-situ monitoring the subsurface wear of materials experiencing both direct and inverse transformations.
\end{abstract}

Keywords: zirconia; transformation toughening; low-temperature degradation; friction; acoustic emission; numerical modeling; movable cellular automata method

\section{Introduction}

Tetragonal zirconia polycrystalline ceramics (TZP) partially stabilized by $3 \mathrm{~mol} \%$ of yttria (3Y-TZP) are a well-known material that makes it possible to combine high strength, fracture toughness, ion conductance, and low thermal conduction. Therefore, they have been evaluated for numerous applications, ranging from thermal barrier coatings to biomedical materials. However, 3Y-TZP is prone to low-temperature degradation (LTD) in a humid atmosphere [1]. The LTD may occur in the $20-400{ }^{\circ} \mathrm{C}$ range when polycrystalline $100 \%$ tetragonal-phase material slowly transforms into a monoclinic zirconia with corresponding fast degradation of strength and fracture toughness. Phase transformation in LTD starts locally and results

* Corresponding author: Nikolai L SAVCHENKO, E-mail: savnick@ispms.ru 
in surface fissuring by means of micro and macro cracks [2]. The LTD may be inhibited by introducing various hard particles, such as alumina, and thus results in a ceramic material composite [3].

The effect of transformation-induced plasticity on Y-TZP wear has been extensively studied. Thus, Fischer et al. [4] investigated the effect of transformationinduced fracture toughness of this ceramic on the wear resistance depending on the dissolved $\mathrm{Y}_{2} \mathrm{O}_{3}$ content. The improved fracture toughness corresponded to high Y-TZP wear resistance. The sliding speed was very low $(0.001 \mathrm{~m} / \mathrm{s})$ to avoid heating the sample.

Sliding tests on Y-TZP should be stopped on reaching the sliding speed value $1 \mathrm{~m} / \mathrm{s}$ to avoid further catastrophic deterioration on the Y-TZP worn surface [5]. The rationale is that the transformation toughening contribution to wear resistance is reduced as the worn surface temperature grows with the sliding speed and becomes closer to the tetragonal-phase stability boundary of $900{ }^{\circ} \mathrm{C}$.

Grinding texture formation for tetragonal and monoclinic peaks in Ce-TZP and Y-TZP materials was explained by friction heating the worn surface layers, which promoted reversible martensite transformation and, thus, caused the crystalline lattice reorientation $[6,7]$.

It is common to discuss the $100 \%$ tetragonal Y-TZP wear against a steel counter body in a sliding speed range of $0.2-0.9 \mathrm{~m} / \mathrm{s}$ in terms of microcutting by ceramic wear particles detached from the sample under the action of the stress exerted by the volume expansion effect of strain-induced martensitic transformation $[8,9]$. Such a wear process may be referred to as mild wearing contrast to the brittle fracture that occurs at higher speeds when strain-induced plasticity is not effective. The LTD-aged samples are less prone to the direct martensite transformation and, therefore, studying wear and friction on them is of interest for the research community.

Deville et al. [2] analyzed in a critical manner the applicability of different analytical methods for characterization of the LTD aging, including X-ray diffraction (XRD), scanning electron microscopy (SEM), optical interferometry (OI), and atomic-force microscopy (AFM). It was shown that both XRD and SEM have limited spatial resolution, which does not allow observing subsurface and superficial structural changes at the first LTD stage, respectively. However, both OI and AFM allow observing the LTD onset stage on the surface of a sample, but no information about subsurface structural changes can be obtained. Also, the AFM observation is confined by small surface areas of interest. Therefore, the above-named methods do not allow obtaining adequately full information about the LTD, and new methods should be applied. One of these methods used for studying LTD in 3Y-TZP is acoustic emission (AE) [10]. It was shown that both the AE count rate and amplitude correlate with LTD evolution and, therefore, may be used for real-time monitoring of the 3Y-TZP structural condition.

There is a lack of studies on the behavior of the LTD-aged 3Y-ZP ceramics in mechanically mated couples, i.e., when the 3Y-TZP subsurface already contains some amount of monoclinic phase, while the mechanical behavior of 3Y-TZP ceramics subjected to LTD is an interesting issue concerning the wide application of these ceramics.

Most of the investigations in the field of $\mathrm{AE}$ monitoring focused on AE monitoring of metallic sliding contacts, and little research was devoted to the $\mathrm{AE}$ monitoring of ceramic ones [11-13]. It was established that the AE signal root mean square (RMS) amplitude is linearly dependent on the friction force work given that the sliding speed is kept constant.

There is another approach to AE signal studies that looks for correlations between the AE signal time-frequency domain values and mechanical loading parameters. The AE signal's most informative parameters are median frequency and power spectral dependencies on time [14-17].

The AE signal sources in sliding wear on zirconiabase ceramics depend on the martensitic transformation. McBride et al. suggested [18] that wear debris removal from the unlubricated sliding contact was characterized by high-amplitude short-rise-time AE signals, while running-in wear and plastic flow resulted in lowamplitude long-rise-time AE signals.

Deformation and fracture processes in zirconiabased materials have been studied using the AE by many researchers [19-22]. Lankford [20] used AE for controlling the deformation and fracture on magnesia partially stabilized zirconia (Mg-PSZ) ceramics in a 
compression test. The AE events occurred only on reaching the yield offset stress, so that the acoustic emission was related to the nonlinear stress-strain curve portion, i.e., the portion whose nonlinearity was determined by martensitic transformation. There was no such nonlinear behavior at elevated temperatures $\left(700^{\circ} \mathrm{C}\right)$ when martensitic transformation became hardly feasible. Further mechanical loading resulted in registering the AE signals from a final catastrophic failure. These observations allowed Lankford to suggest that AE signals have been generated only by a microfracture dissipation mechanism and not by the transformation itself.

Drozdov et al. [21] established that AE signals during a transformation-induced plastic deformation stage on zirconia-base materials have been generated by microcracking under tensile loading. The AE count rate was in good correlation to the crack size and propagation velocity. Therefore, AE signals in sliding friction are generated by the subsurface cracks that are responsible for the wear particle formation. It was found earlier that crack propagation caused by sliding might be detected by median frequency drops [14-16].

Another fast-developing trend in studying the integral martensitic transformation as well as the LTD phenomenon is computer-aided modeling. Numerical approaches in the field of modeling the wear and friction processes occurring in Y-TZP-base ceramics face the necessity of modeling the martensitic transformation effects; therefore, a continuous theoretical description of integral martensitic transformation manifestations in materials (including 3Y-TZP) is traditionally performed using associated plastic flow models based on different yield criteria [23-27]. Experimental investigations show that both first and second stress tensor invariants (or equivalent stress and mean/hydrostatic stress, respectively) should be included with these yield criteria [23]. The necessity of considering the hydrostatic stress is determined by the high value of volume change, $4 \%$ to $5 \%$, that occurs during direct or inverse martensitic phase transformation and by a significant contribution of localized dilatancy/compaction to toughening/ embrittlement.

The well-known examples of the above-described models are various versions of the two-parameter micromechanical Hwang-Lagoudas model, which makes allowance for the hydrostatic stress contribution into the yield criteria in the form of linear approximation [23-27]. Characteristic 3Y-TZP values of a volume expansion strain of $4 \%$ to $5 \%$ and a lattice shear of $7 \%$ to $16 \%$ are used as the two-parameter model yield criterion parameters. Despite giving noticeable advantages, the use of these "localized" models for description of inelastic deformation in volumes that partially experienced martensitic transformation is complicated by the necessity of introducing extra new phase growth kinetic models. Furthermore, the generation of transformation-induced shear bands gives highly distorted localized stress fields, which serve to nucleate microcracks and, thus, further contribute to inelastic volume expansion (dilatancy) [28]. The latter fact is, as a rule, not considered within the frameworks of the above-described plastic flow models. At the same time, the key integral manifestations of such a combined transformation/ microcrack-induced plasticity mechanism could be adequately described using general mathematical models based on the nonassociated plastic flow rule.

A key feature of those models is introducing an extra integral parameter, such as a dilation rate, as well as a specific ratio that makes it possible to determine the dilation rate dynamics in the course of inelastic deformation. The well-known example of such a model is the Nikolaevsky nonassociated plastic flow model based on the von Mises-Schleicher yield criterion [29-30]. Note that structural form of this criterion is a full analogue of the Hwang-Lagoudas micromechanical criterion as well as the Nikolaevsky model parameters can be estimated, among others, from those of micromechanical model. The Nikolaevsky model has originally been formulated for description of a microcrack-induced dilatant inelastic behavior of brittle rocks and ceramics. However, its generality and independence of the localized stress relaxation mechanisms allowed using it for modeling the mechanical behavior of Y-TZP (as well as Y-TZP- $\mathrm{Al}_{2} \mathrm{O}_{3}$ ceramics) under pressure/temperature (PT) conditions favorable for direct phase transformation accompanied by material dilation [31].

Wear in ceramics is mainly by subsurface fracture. Therefore, this model is used here for a numerical study of the subsurface damages accumulated in Y-TZP and $\mathrm{Y}-\mathrm{TZP}-\mathrm{Al}_{2} \mathrm{O}_{3}$ ceramic materials during sliding. 
This research combines the results of experimental and numerical studies of the effect of transformationinduced plasticity on the subsurface fracture. The objective of this research is to understand how direct and inverse transformations occur during the wear and friction in LTD-aged Y-TZP/steel and Y-TZP- $\mathrm{Al}_{2} \mathrm{O}_{3} /$ steel and establish correlations with the $\mathrm{AE}$ and vibration acceleration signal parameters.

\section{Material and methods}

The ceramic samples had a chemical composition as follows: $97 \mathrm{~mol} \% \mathrm{ZrO}_{2}+3 \mathrm{~mol} \% \mathrm{Y}_{2} \mathrm{O}_{3}(\mathrm{Y}$-TZP) and $80 \mathrm{wt} \% \mathrm{ZrO}_{2}\left(3 \mathrm{~mol} \% \mathrm{Y}_{2} \mathrm{O}_{3}\right)+20 \mathrm{wt} \% \mathrm{Al}_{2} \mathrm{O}_{3}$ (Y-TZP$\mathrm{Al}_{2} \mathrm{O}_{3}$ ). Freshly sintered Y-TZP and Y-TZP- $\mathrm{Al}_{2} \mathrm{O}_{3}$ samples had $5 \%$ porosity and contained $100 \%$ tetragonal-phase zirconia. These samples were stored for more than 20 years at the room temperatures and humidity. The resulting LTD-aged samples contained both tetragonal/ monoclinic phases at ratios of $64 / 36$ and $75 / 25$, for Y-TZP and Y-TZP- $\mathrm{Al}_{2} \mathrm{O}_{3}$, respectively. The LTD-aged samples revealed multiple instances of spalling and microcracking on their surfaces formed as a result of tetragonal-to-monoclinic transformation.

The tribological behavior of the samples was studied using a pin-on-disk scheme and TRIBO technic tribometer. The ceramic samples were $3 \mathrm{~mm} \times 3 \mathrm{~mm}$ in cross-section area and 10-mm-high pins. The disk's surfaces were mechanically ground to roughness $\mathrm{Ra}=$ $0.32 \mu \mathrm{m}$. The sliding speed and path were $0.5 \mathrm{~m} / \mathrm{s}$ and $1 \mathrm{~m} / \mathrm{s}$, respectively. Normal loads were $13 \mathrm{~N}$ and $26 \mathrm{~N}$. After testing, the worn surfaces of the ceramic samples were examined using an optical microscope Altami MET 1C. XRD studies of the polished surfaces were performed using an XRD instrument DRON 3.0, $40 \mathrm{kV}$, $22 \mu \mathrm{A}$, and $\mathrm{Cu}-\mathrm{K}_{\alpha}$ radiation in the $2 \theta$ range $26^{\circ}-38^{\circ}$.

An EYa-2 setup (Togliatti State University) attached with a MSAE-L230-1000kHz bandpass 20-mm-diameter sensor was used to receive and analyze the acoustic emission signals. Parasite signals generated by the mechanical system were removed by means of a $50 \mathrm{kHz}$ highpass LC-filter. The AE signal sampling rate was $1 \mathrm{kHz}$. Therefore, an AE signal envelope characterized the slowly occurring processes. The quickly occurring processes were characterized by the AE $0.021 \mathrm{~s}$ duration frames recorded at sampling rate $6.25 \mathrm{MHz}$. The AE frames were analyzed together with the simultaneously obtained vibration acceleration signal. Special software was developed for determining median frequency values for each frame using the short-time Fourier transformation (STFT) with a rectangle 1000-data-point window size and 300-point length shift. Doing so enabled the time dependencies of these characteristics to be reconstructed for the full signal duration.

The vibration acceleration signals were registered by an IMI industrial accelerometer and USB data logger NI-9234 (National Instruments) at a sampling rate $25.6 \mathrm{kHz}$. The running root mean square (run RMS) of acceleration was calculated for 1-s signal acquisition periods.

\section{Results}

Experimental time dependencies characterizing the friction coefficient, AE median frequency, AE signal energy, and RMS vibrational accelerations in two perpendicular planes are shown in Fig. 1, Fig. 2, Fig. 4, and Fig. 5 for different sliding-speed and normal-load values as obtained on LTD-aged Y-TZP/steel and Y-TZP- $\mathrm{Al}_{2} \mathrm{O}_{3} /$ steel couples.

\section{$3.1 \quad \mathrm{Y}-\mathrm{TZP} /$ steel}

\subsubsection{Friction coefficient}

Sliding at $0.5 \mathrm{~m} / \mathrm{s}$ and $13 \mathrm{~N}$ load (Fig. 1(a)) was characterized by high-frequency and low-frequency friction coefficient oscillations in the range $\sim 0.05-0.64$. The low-frequency oscillation period was approximately $1,000 \mathrm{~s}$. Increasing the normal load to $26 \mathrm{~N}$ resulted in increasing the friction coefficient range to $\sim 0.05-0.92$ (Fig. 1(b)).

Sliding at $1 \mathrm{~m} / \mathrm{s}$ and $13 \mathrm{~N}$ load (Fig. 2(a)) was in steady friction mode with an almost constant friction coefficient 0.2 until approximately the 1800th s, which then changed for high-amplitude oscillation mode in the range $\sim 0.07-0.42$. Sliding at $1 \mathrm{~m} / \mathrm{s}$ and $26 \mathrm{~N}$ was characterized by a short running-in period and then high-amplitude oscillations in the range $\sim 0.09-0.6$ (Fig. 2(b)).

\subsubsection{AE signal median frequency}

Y-TZP/steel, $0.5 \mathrm{~m} / \mathrm{s}$. The AE signal median frequency 

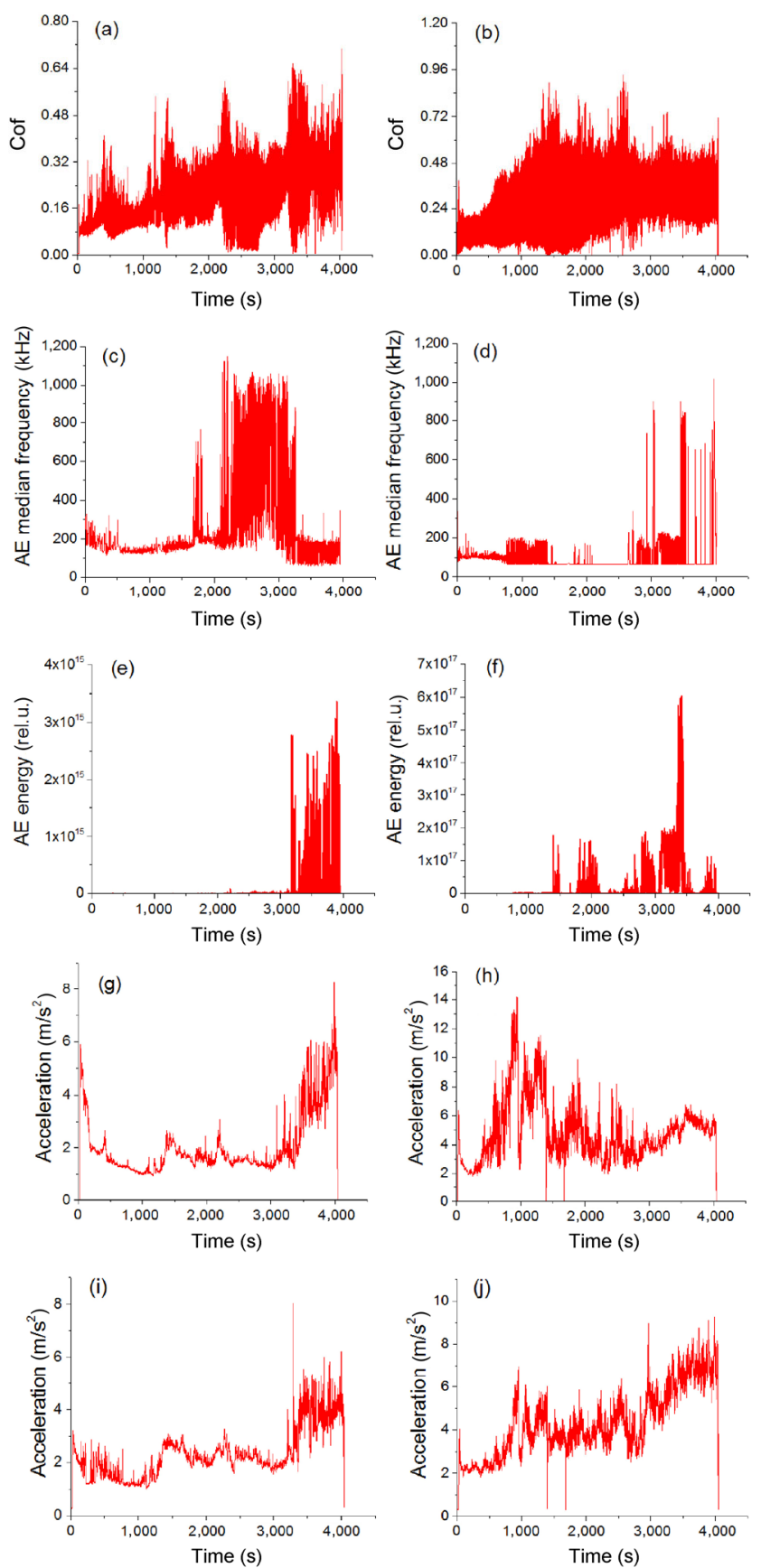

Fig. 1 Time dependencies of friction coefficient ((a), (b)), AE median frequency ((c), (d)), AE energy ((e), (f)), and vertical ((g), (h)) and horizontal ((i), (j)) vibration acceleration RMS for Y-TZP ceramics obtained in sliding at $0.5 \mathrm{~m} / \mathrm{s}, 13 \mathrm{~N}$ ((a), (c), (e), (g), (i)) and $26 \mathrm{~N}$ ((b), (d), (f), (h), (j)) normal load.

(MF) stays almost constant until approximately the 1700th s, when it shows first a narrow high-frequency burst and then a set of bursts of even higher frequency (Fig. 1(c)). Increasing the normal load to $26 \mathrm{~N}$ gives a row of $75-215 \mathrm{kHz}$ frequency peaks, which then
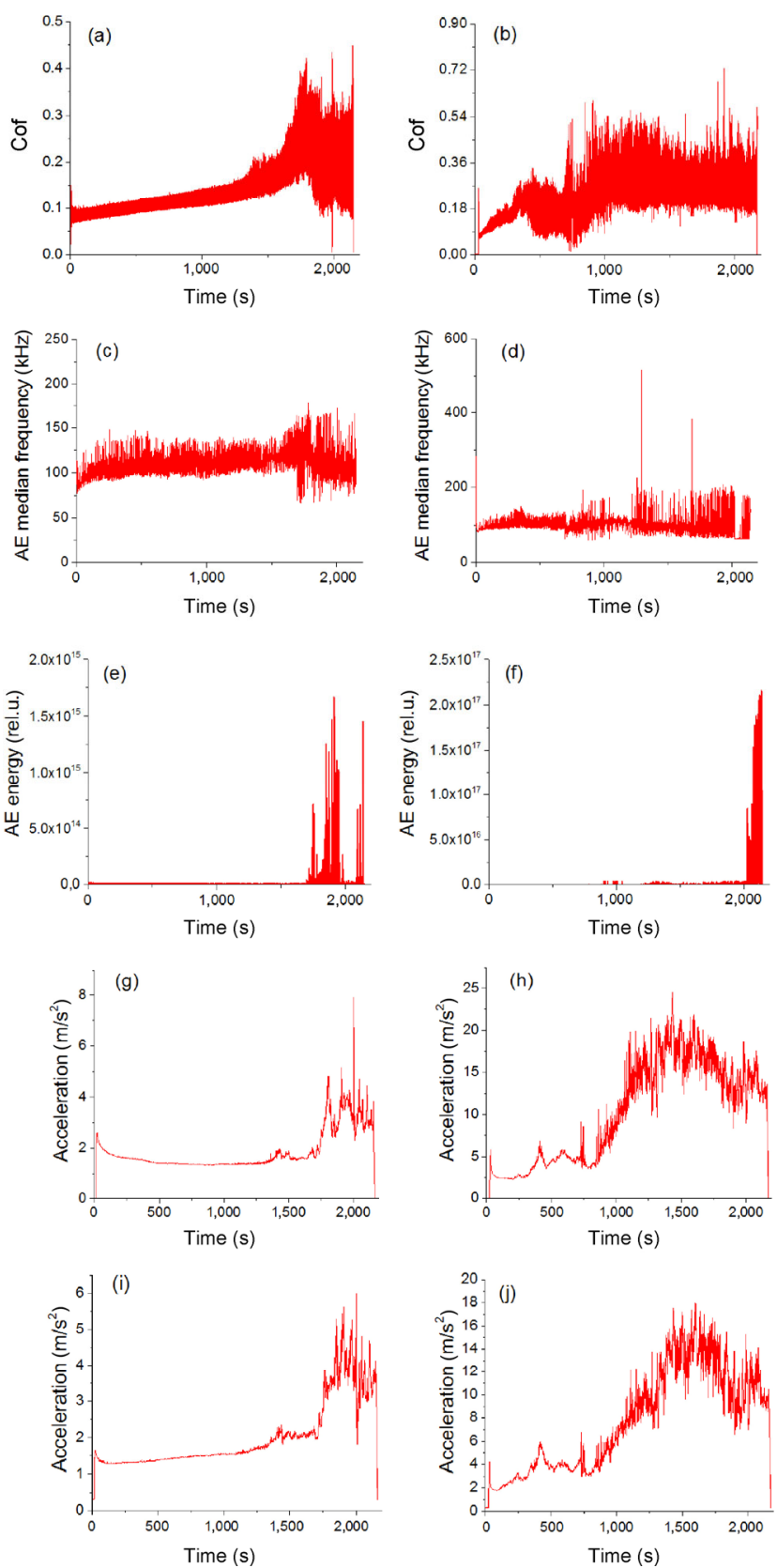

Fig. 2 Time dependencies of friction coefficient ((a), (b)), AE median frequency ((c), (d)), AE energy ((e), (f)), and vertical ((g), (h)) and horizontal ((i), (j)) vibration acceleration RMS for Y-TZP ceramics obtained in sliding at $1 \mathrm{~m} / \mathrm{s}, 13 \mathrm{~N}((\mathrm{a}),(\mathrm{c}),(\mathrm{e})$, (g), (i)) and $26 \mathrm{~N}$ ((b), (d), (f), (h), (j)) normal load.

disappear (Fig. 1(d)). High-frequency $1 \mathrm{MHz}$ narrow bursts arise again from 2600th s (Fig. 1(d)).

MF histograms in Figs. 3(a) and 3(c) show that the values are predominantly in the frequency range of $55-300 \mathrm{kHz}$ for sliding at a normal load of $13 \mathrm{~N}$. For a $0.5 \mathrm{~m} / \mathrm{s}$ sliding speed, there is a high-frequency 300 $1,050 \mathrm{kHz}$ tail (Fig. 3(a)). Sliding at a higher normal 

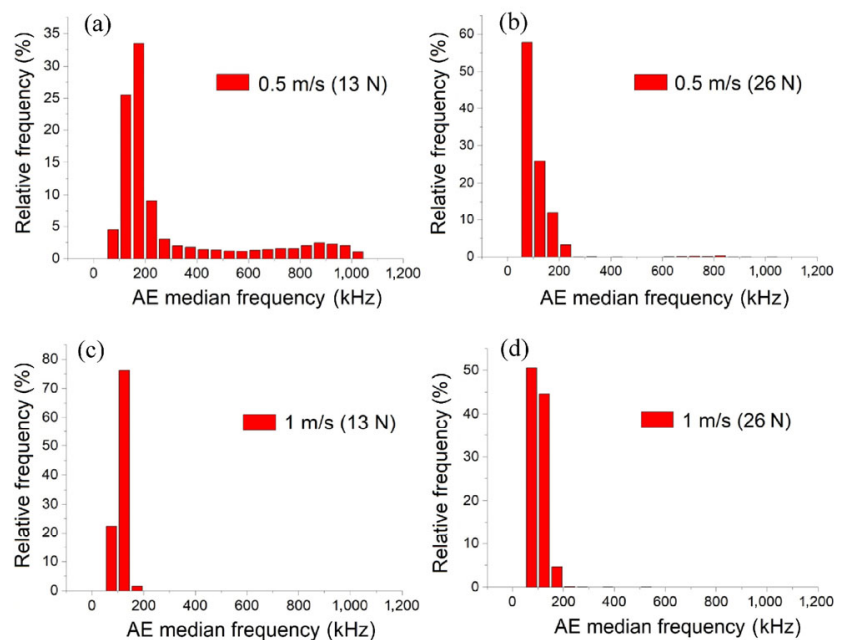

Fig. 3 Median frequency distribution histograms for Y-TZP in sliding at $0.5 \mathrm{~m} / \mathrm{s} 13 \mathrm{~N}$ (a) and $26 \mathrm{~N}$ (b) and at $1 \mathrm{~m} / \mathrm{s} 13 \mathrm{~N}$ (c) and $26 \mathrm{~N}(\mathrm{~d})$.

load of $26 \mathrm{~N}$ shifts the distribution to the lower frequency end (i.e., $55-225 \mathrm{kHz}$ ) leaving a small amount of high-frequency $600-1,060 \mathrm{kHz}$ peaks (Figs. 3(b) and $3(\mathrm{~d}))$.

$Y$-TZP/steel, $1 \mathrm{~m} / \mathrm{s}$. The median frequency changes in the range 75 to $175 \mathrm{kHz}$ at a normal load of $13 \mathrm{~N}$ (Fig. 2(c)). The $26 \mathrm{~N}$ sliding is accompanied by nonsteady MF growth in the $70-225 \mathrm{kHz}$ range (Fig. 2(d)). MF histograms (Figs. 3(c) and 3(d)) show a narrow MF distribution within $55-175 \mathrm{kHz}$ for samples tested at $1 \mathrm{~m} / \mathrm{s} 13 \mathrm{~N}$ (c) and $1 \mathrm{~m} / \mathrm{s} 26 \mathrm{~N}$ (d).

\subsubsection{AE energy}

$Y$-TZP/steel, $0.5 \mathrm{~m} / \mathrm{s}$. The AE energy plot shows almost no changes during the first 3,200 s period of sliding at a $13 \mathrm{~N}$ load (Fig. 1(e)). High peaks appear starting from the 3200th s. Sliding at a higher load of $26 \mathrm{~N}$ gives a set of medium-amplitude peak groups as well as one high-amplitude one (Fig. 1(f)) starting from 1300th s.

Y-TZP/steel, $1 \mathrm{~m} / \mathrm{s}$. The first high-energy peaks appear after sliding for $1,600 \mathrm{~s}$ and 2,000 $\mathrm{s}$ at a $13 \mathrm{~N}$ and $26 \mathrm{~N}$ load, respectively (Figs. 2(e) and 2(f)).

\subsubsection{Vibration acceleration in vertical and horizontal planes}

Y-TZP/steel, $0.5 \mathrm{~m} / \mathrm{s}$. Vertical and horizontal plane vibration acceleration RMS values stay below the $4 \mathrm{~m} / \mathrm{s}^{2}$ range during sliding at a $13 \mathrm{~N}$ load until reaching a 3,200 s time at which they start sharply growing to 8 and $6 \mathrm{~m} / \mathrm{s}^{2}$, respectively (Figs. $1(\mathrm{~g})$ and $1(\mathrm{i})$ ). The vertical and horizontal vibration acceleration RMS values show sequences of peaks whose heights decay and grow, respectively, depending on the $26 \mathrm{~N}$ sliding test time (Figs. 1(h) and 1(j)).

$Y$-TZP/steel, $1 \mathrm{~m} / \mathrm{s}$. The vertical and horizontal vibroaccelerations are low and in a steady mode from the beginning of the sliding under a $13 \mathrm{~N}$ load (Figs. 2(g) and 2(i)). The first high-amplitude vibrations in sliding at $13 \mathrm{~N}$ and $26 \mathrm{~N}$ appear starting from 1500th $\mathrm{s}$ and 1000th s, respectively (Figs. 2(g)-2(j)).

\section{$3.2 \mathrm{Y}-\mathrm{TZP}-\mathrm{Al}_{2} \mathrm{O}_{3} /$ steel}

\subsubsection{Friction coefficient}

Sliding composite ceramics $\mathrm{Y}-\mathrm{TZP}-\mathrm{Al}_{2} \mathrm{O}_{3}$ against steel is accompanied by high-amplitude friction force oscillations for $13 \mathrm{~N}$ and $26 \mathrm{~N}$ loads at $0.5 \mathrm{~m} / \mathrm{s}$ (Figs. 4(a) and $4(\mathrm{~b})$ ). The same type of behavior is exhibited at a $1 \mathrm{~m} / \mathrm{s}$ sliding speed (Figs. 5(a) and 5(b)).

A diagram in Fig. 6(a) shows that increasing the normal load resulted in increasing the mean friction coefficient while increasing the sliding speed to reduce it. The mean friction coefficient values of Y-TZP/steel were higher than those of the $\mathrm{Y}-\mathrm{TZP}-\mathrm{Al}_{2} \mathrm{O}_{3} /$ steel couple.

\subsubsection{AE signal median frequency}

Y-TZP- $\mathrm{Al}_{2} \mathrm{O}_{3} / \mathrm{steel}, 0.5 \mathrm{~m} / \mathrm{s}$. MF starts increasing from the beginning of the sliding at $13 \mathrm{~N}$, thus reaching a maximum value of $250 \mathrm{kHz}$ (Fig. 4(c)) at the 3250th s and then diminishing to $70 \mathrm{kHz}$. A higher load of $26 \mathrm{~N}$ gives a background MF level of approximately $100 \mathrm{kHz}$ with a $500 \mathrm{~s}$ duration group of bursts starting at the 750th s (Fig. 5(c)). The MF histograms demonstrate (Figs.7(a) and 7(b)) that sliding at $13 \mathrm{~N}$ provides an uneven MF distribution with a predominating low-frequency and fewer AE highfrequency events. The distribution becomes greater even in sliding at $26 \mathrm{~N}$ with the peak value in the range of $75-125 \mathrm{kHz}$ as well as a smaller group of 125-275 kHz signals.

$Y-T Z P-A l_{2} \mathrm{O}_{3} /$ steel, $1 \mathrm{~m} / \mathrm{s}$. Increasing the sliding velocity had only a minor effect of MF for normal load values of $13 \mathrm{~N}$ and $26 \mathrm{~N}$ (Figs. 4(c) and 4(d) and Figs. 5(c) and 5(d)). According to the diagrams in Fig. 3 and Figs. 7(c) and 7(d), mean MF values for both Y-TZP/ steel and $\mathrm{Y}-\mathrm{TZP}-\mathrm{Al}_{2} \mathrm{O}_{3} /$ steel couples fall into the 

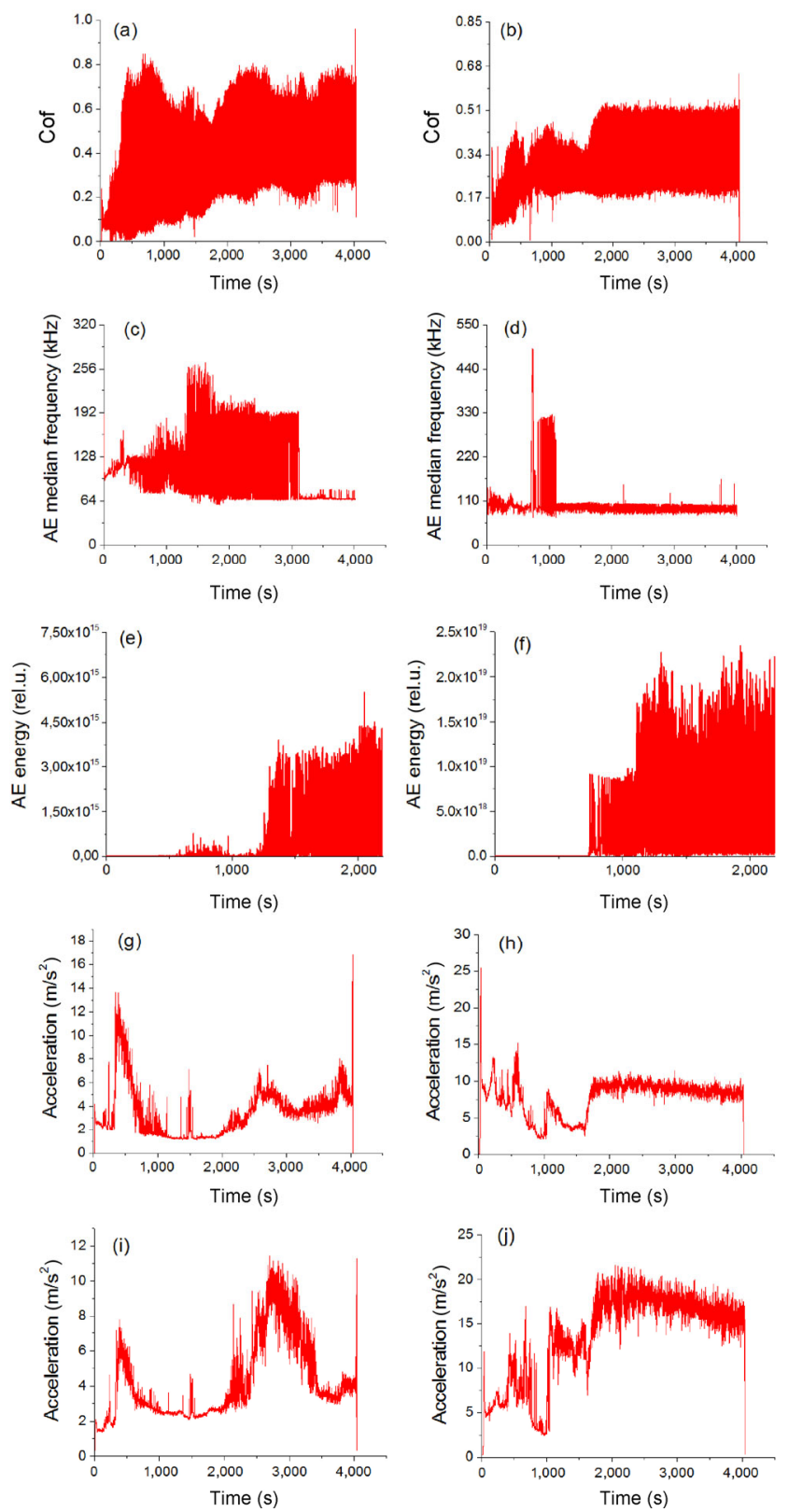

Fig. 4 Time dependencies of friction coefficient ((a), (b)), AE median frequency ((c), (d)), AE energy ((e), (f)), and vertical ((g), (h)) and horizontal ((i), (j)) vibration acceleration RMS for Y-TZP- $\mathrm{Al}_{2} \mathrm{O}_{3}$ ceramics obtained in sliding at $0.5 \mathrm{~m} / \mathrm{s}, 13 \mathrm{~N}((\mathrm{a})$, (c), (e), (g), (i)), and $26 \mathrm{~N}$ ((b), (d), (f), (h), (j)) normal load.

75-200 kHz range. Maximal MF was found for Y-TZP/ steel at $0.5 \mathrm{~m} / \mathrm{s}$ and $13 \mathrm{~N}$. All other speed and load combinations provide $\mathrm{MF}$ values higher than those obtained from the Y-TZP/steel couple.

\subsubsection{AE energy}

$Y$-TZP- $\mathrm{Al}_{2} \mathrm{O}_{3} /$ steel, $0.5 \mathrm{~m} / \mathrm{s}$. A medium-energy peak group formed after sliding for 2,400 s at $13 \mathrm{~N}$ and then
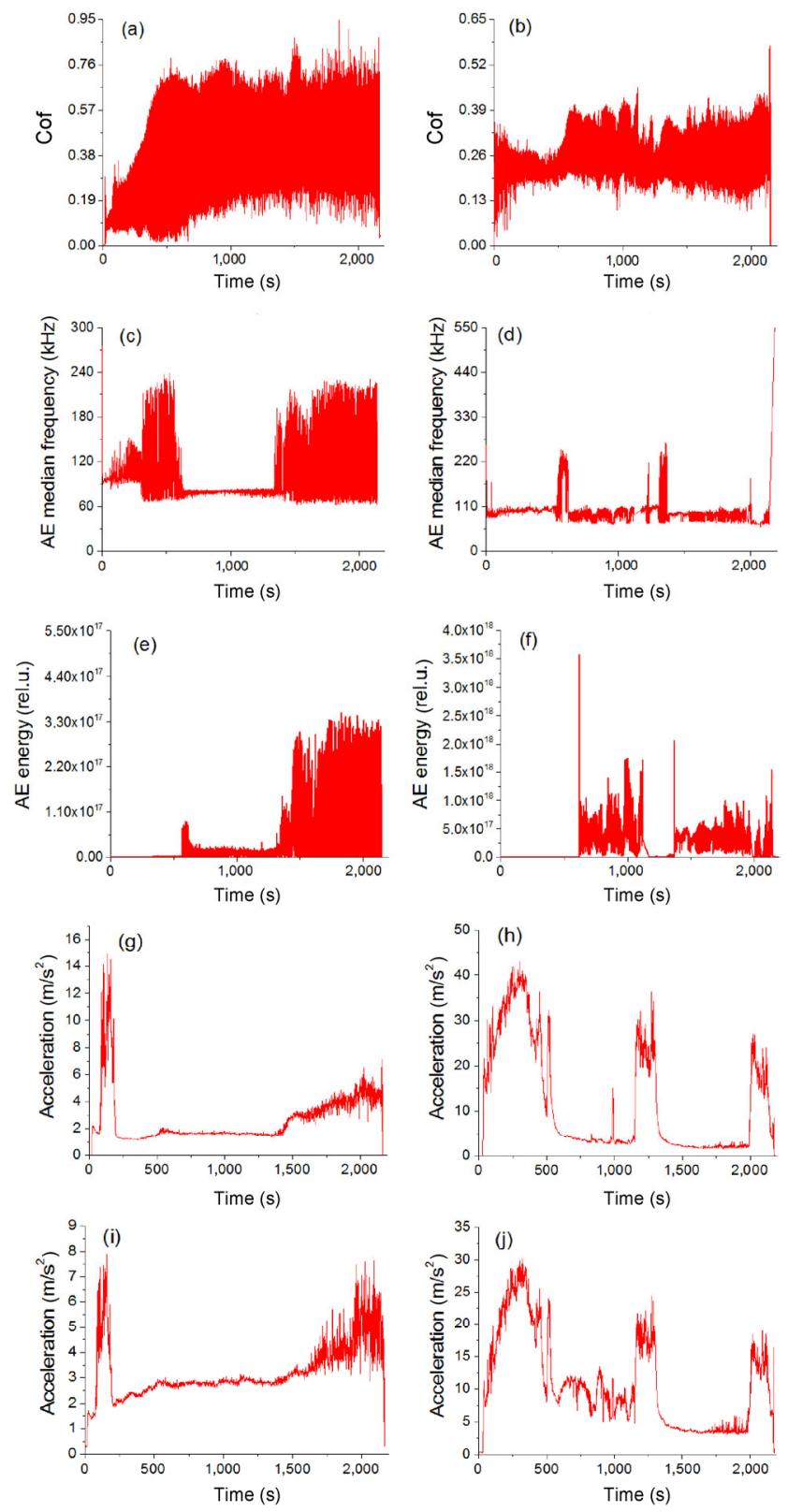

Fig. 5 Time dependencies of friction coefficient ((a), (b)), AE median frequency ((c), (d)), AE energy ((e), (f)), and vertical ((g), (h)) and horizontal ((i), (j)) vibration acceleration RMS for Y-TZP- $\mathrm{Al}_{2} \mathrm{O}_{3}$ ceramics obtained in sliding at $1 \mathrm{~m} / \mathrm{s}, 13 \mathrm{~N}((\mathrm{a}),(\mathrm{c})$, (e), (g), (i)), and $26 \mathrm{~N}$ ((b), (d), (f), (h), (j) normal load.

changed for a high-energy peak group, thus forming a steplike diagram in Fig. 4(e). Analogous AE energy behavior was observed for sliding at a $26 \mathrm{~N}$ load (Fig. 4(f)). The first medium energy peak group formed after sliding for $750 \mathrm{~s}$ and then quickly changed for almost-constant-height high-energy peaks (Fig. 4(f)).

$Y-T Z P-\mathrm{Al}_{2} \mathrm{O}_{3} / \mathrm{steel}, 1 \mathrm{~m} / \mathrm{s}$. Medium energy peaks were observed after $13 \mathrm{~N}$ load sliding for $550 \mathrm{~s}$ (Fig. 5(e)) 
and then changed for the high-energy peaks according to the above-described two-step plot pattern. Another type of behavior was observed for sliding at a $26 \mathrm{~N}$ load when two almost-equal height peak groups appear (Fig. 5(f)). The minimum AE energy value was observed in the case of $\mathrm{Y}-\mathrm{TZP}-\mathrm{Al}_{2} \mathrm{O}_{3} /$ steel sliding (Fig. 6(c)).
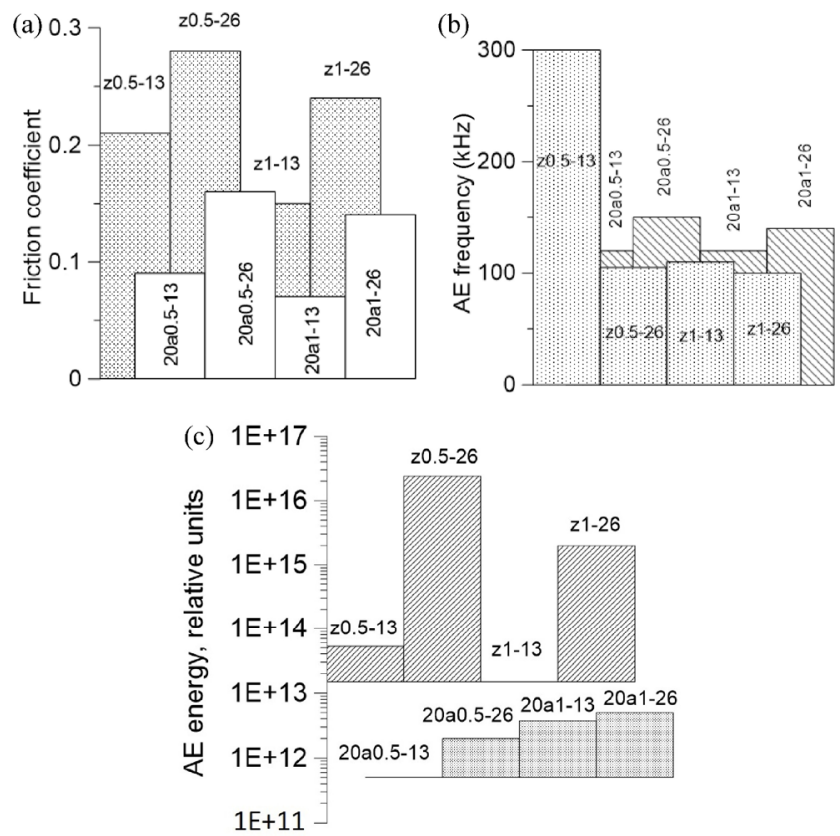

Fig. 6 Diagrams showing (a) mean friction coefficient values, (b) mean $\mathrm{AE}$ median frequency values, and (c) mean $\mathrm{AE}$ energy values for Y-TZP (z) and Y-TZP- $\mathrm{Al}_{2} \mathrm{O}_{3}$ (20a) samples. The first number after the material index (" $\mathrm{z}$ " or " $20 \mathrm{a}$ ") denotes the sliding velocity $(0.5 \mathrm{~m} / \mathrm{s}$ or $1 \mathrm{~m} / \mathrm{s})$, while the second index corresponds to the normal load value $(13 \mathrm{~N}$ or $26 \mathrm{~N})$.
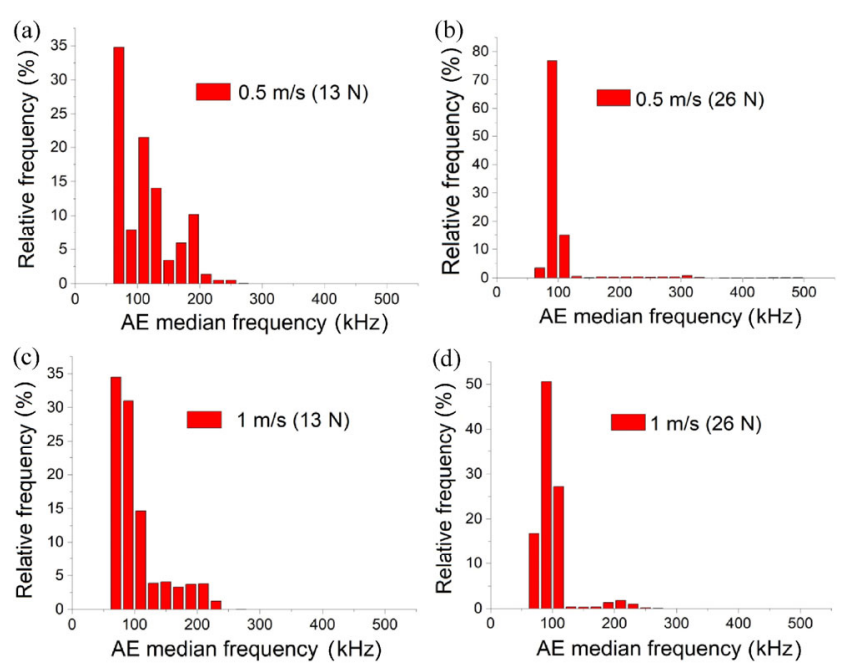

Fig. 7 Median frequency distribution histograms for $\mathrm{Y}-\mathrm{TZP}-\mathrm{Al}_{2} \mathrm{O}_{3}$.

\subsubsection{Vibration acceleration in vertical and horizontal planes}

Y-TZP- $\mathrm{Al}_{2} \mathrm{O}_{3} / \mathrm{steel}, \quad 0.5 \mathrm{~m} / \mathrm{s}$. Vertical and horizontal vibro-acceleration RMS values showed their first $14 \mathrm{~m} / \mathrm{s}^{2}$ and $7.8 \mathrm{~m} / \mathrm{s}^{2}$ peaks in the range 0 to $1,000 \mathrm{~s}$ for sliding at a $13 \mathrm{~N}$ load (Figs. 4(g) and 4(i)). Gradual reducing vibro-acceleration RMS values were observed until the 2000th s, when high peaks appeared. The horizontal RMS's second peak was higher than that of vertical one. Sliding at $26 \mathrm{~N}$ provided another RMS dependence pattern when medium-height irregular peaks existed from the beginning of the process, and then it changed for low-amplitude ones, thus revealing steady-mode load-sliding stages for vertical and horizontal vibro-accelerations (Figs. 4(h) and 4(j)). Again, horizontal vibro-acceleration RMS values are higher than those of vertical.

$Y$-TZP- $\mathrm{Al}_{2} \mathrm{O}_{3} / \mathrm{steel}, 1 \mathrm{~m} / \mathrm{s}$. For $13 \mathrm{~N}$ sliding, two RMS peaks were observed when the first sharp and high peak arose close to the sliding onset point, and the second irregular and wide one appeared starting at the 1500th s (Figs. 5(g) and 5(i)). A more complicated pattern was observed in the case of sliding at a $26 \mathrm{~N}$ load. There were three peaks followed by reducing RMS amplitudes (Figs. 5(h) and 5(j)). The vertical and horizontal vibro-accelerations were low and in a steady mode from the beginning of the sliding under a $13 \mathrm{~N}$ load. The first high-amplitude vibrations in sliding at $13 \mathrm{~N}$ and $26 \mathrm{~N}$ appear starting from the 1500th s and 1000th s, respectively (Figs. 5(g) $-5(\mathrm{j})$ ).

\subsection{Structural and phase evolution of worn surfaces}

Y-TZP worn surfaces were more rough with the presence of cracks and spalling than those on Y-TZP$\mathrm{Al}_{2} \mathrm{O}_{3}$ (Fig. 8).

The worn surfaces of all samples contained both monoclinic and tetragonal phases. The amount of

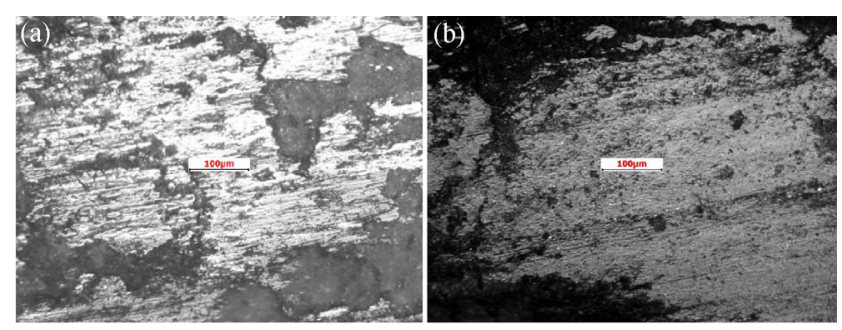

Fig. 8 Optical microscopy images of Y-TZP (a) and Y-TZP- $-\mathrm{Al}_{2} \mathrm{O}_{3}$ (b) worn surfaces on sliding at $1 \mathrm{~m} / \mathrm{s} 26 \mathrm{~N}$. 
monoclinic phase on the worn surface reduced by $10 \%$ compared with that of as-received LTD samples, resulting in 55\% in Y-TZP monoclinic and $65 \%$ in Y-TZP- $\mathrm{Al}_{2} \mathrm{O}_{3}$.

Another finding was that the worn surfaces revealed some XRD texturing, which is determined as the $\mathrm{ZrO}_{2}$ tetragonal-phase XRD peak intensity ratio $\mathrm{I}_{(002)} / \mathrm{I}_{(200)}$. This ratio is increased by sliding and becomes higher than the 0.5 value inherent in the random crystalline lattice orientation as determined from XRD on the freshly polished ceramics surface. This ratio becomes higher than 0.8 and is applicable to the $\mathrm{ZrO}_{2}$ monoclinic-phase $X R D$ peak ratio $\mathrm{I}_{(11-1)} / \mathrm{I}_{(111)}$.

In the case of $\mathrm{Y}-\mathrm{TZP}-\mathrm{Al}_{2} \mathrm{O}_{3}$, the tetragonal $\mathrm{I}_{(002)} / \mathrm{I}_{(200)}$ and monoclinic $\mathrm{I}_{(11-1)} / \mathrm{I}_{(111)}$ ratios were higher than those of Y-TZP for all sliding speed and load combinations (Fig. 9). This may tell much about sliding-induced transformation in the LTD-aged ceramics. This was investigated from the standpoint of AE parameters, which may denote the effect of the transformation on sliding.

Possible correlations among the friction coefficient, XRD, and AE parameters are shown in Fig. 10 and Fig. 11. The AE energy/friction coefficient and friction coefficient/XRD peak ratios are also shown in Fig. 10 and Fig. 11. There is a correlation between the $\mathrm{AE}$ energy and friction coefficient (Fig. 10). Furthermore, the minimal AE energy and friction coefficient values correspond to those of $\mathrm{Y}-\mathrm{TZP}$ and $\mathrm{Y}-\mathrm{TZP}-\mathrm{Al}_{2} \mathrm{O}_{3}$ ceramic samples, demonstrating high $\mathrm{ZrO}_{2}$ tetragonal $\mathrm{I}_{(002)} / \mathrm{I}_{(200)}$ and monoclinic $\mathrm{I}_{(11-1)} / \mathrm{I}_{(111)}$ ratios.

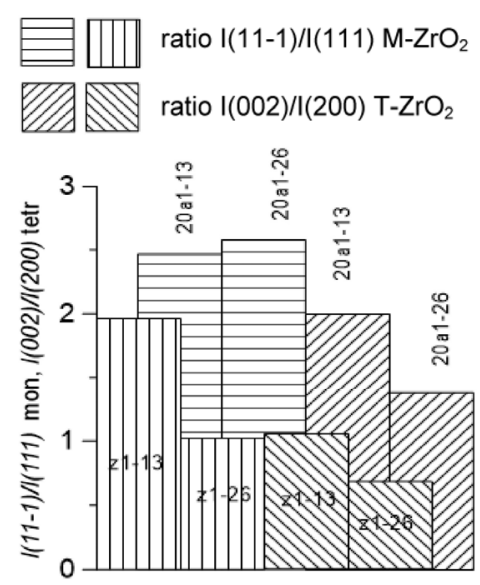

Fig. 9 Monoclinic and tetragonal-phase peak intensity ratios $\mathrm{I}_{11-1} / \mathrm{I}_{111}$ and $\mathrm{I}_{002} / \mathrm{I}_{200}$, respectively, for Y-TZP (z) and Y-TZP- $\mathrm{Al}_{2} \mathrm{O}_{3}$ (20a) after sliding at $1 \mathrm{~m} / \mathrm{s} 13 \mathrm{~N}(1-13)$ and $1 \mathrm{~m} / \mathrm{s} 26 \mathrm{~N}(1-26)$.

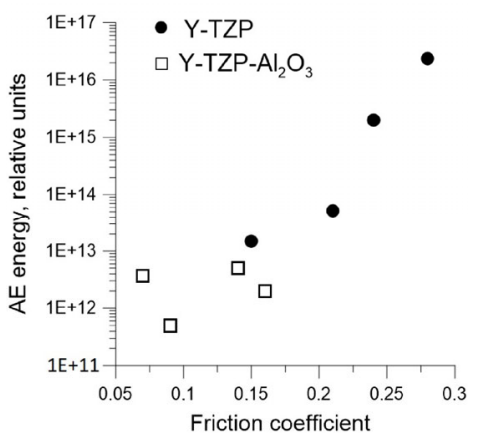

Fig. 10 AE energy vs. friction coefficient.
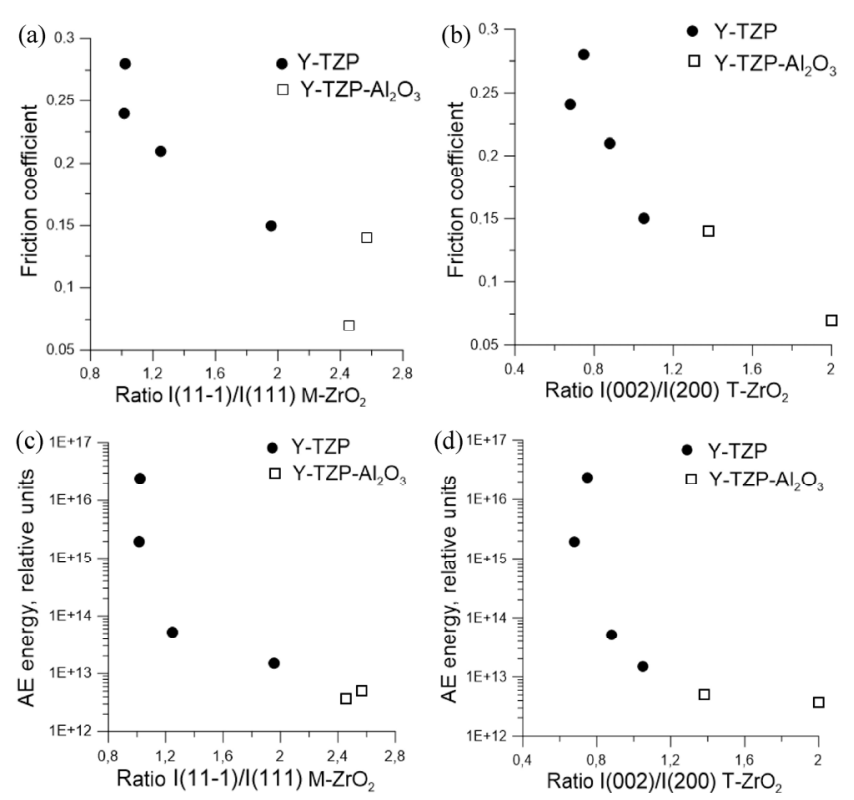

Fig. 11 Monoclinic-phase peak $\mathrm{I}_{002} / \mathrm{I}_{200}$ (a) and tetragonal $\mathrm{I}_{11-1} / \mathrm{I}_{111}$ (b) peak intensity dependencies of friction coefficient and $\mathrm{AE}$ energy ((c) and (d)).

\section{MCA modeling}

A numerical 2D movable cellular automata (MCA) method was used to gain more understanding of the subsurface tribological behavior of both composites. The MCA method is one of the so-called "explicit" discrete-elements methods (DEMs) when the evolution of an ensemble of discrete elements is defined by a numerical solution of the system of classical equations of motion using an explicit numerical scheme. Specific features of this method of 2D implementation are as follows: (1) approximation of equivalent disks for interpreting the element shape when numerically solving equations of motion (this makes it possible to use simplified Newton-Euler equations of motion); (2) approximation of homogeneous distribution of strain 
and stresses in the volume of discrete elements (the stress-strain state of a discrete element is determined by the average stress tensor $\sigma_{\alpha \beta}$ and average strain tensor $\varepsilon_{\alpha \beta}$ ); (3) element-element interaction forces are formulated in the framework of the original manybody form with the use of average stresses and strains [32-35]. To describe the elastic behavior of the Y-TZP and Y-TZP- $\mathrm{Al}_{2} \mathrm{O}_{3}$ ceramic materials within the MCA framework, a model of locally isotropic linear Hook's law materials is used. The inelastic behavior of discrete elements used for Y-TZP simulation have been described using the pressure-dependent Nikolaevsky's plastic flow model [34]. This model is based on the nonassociated plastic flow rule and Mises-Schleicher criterion $\Phi=\omega J_{1}+\sqrt{J_{2}}=3 \omega \sigma_{\text {mean }}+\sigma_{\text {eq }} / \sqrt{3}$, where $J_{1}$ and $J_{2}$ are the first stress tensor invariant and second stress tensor deviator, respectively; $\omega$ is the dimensionless parameter proportional to the internal friction coefficient $\alpha(\alpha=3 \omega)$; $\sigma_{\text {mean }}$ is the mean stress; and $\sigma_{\mathrm{eq}}$ is the stress intensity. A limiting state condition for the discrete-element volume is defined by breaking the equality as follows [30]:

$$
\Phi=Y
$$

where $Y$ is the value of yield stress under the condition of pure shear (cohesion). An important feature of Nikolaevsky's model is a postulated linear relation between the rates of shear and bulk plastic strains with the dilatancy factor $\Lambda$ [29]:

$$
\dot{I}_{1}^{p}=2 \Lambda \sqrt{\dot{I}_{2}^{p}}
$$

where $\dot{I}_{1}^{p}$ is the first invariant of plastic deformation rate tensor, and $\dot{I}_{2}^{p}$ is the second invariant of the plastic deformation rate tensor. The necessity for using the nonassociated plastic flow rule for describing the transformation-induced inelastic behavior of Y-TZP is dictated by the rather high value of dilatancy achieved as a result of this transformation. An extra contribution is given by microcracks formed near the localized transformation shear bands because of high local distortion of the stress fields.

This localized fracture within the MCA method is modeled by an unlinked state of two automata, which is opposed to the normally linked (bonded) state. The automata state is changed on achieving either the strength limit for ductile materials or a multiparameter criterion in the case of brittle materials. The Drucker-Prager [36] pressure-dependent criterion is used in this work as a fracture criterion:

$$
\sigma_{e q} 0.5(a+1)+\sigma_{\text {mean }} 1.5(a-1) \geq \sigma_{c}
$$

where $\sigma_{\mathrm{c}}$ is the strength limit, $\sigma_{\mathrm{t}}$ is the tensile strength, and $\sigma_{\text {mean }}$ and $\sigma_{\text {eq }}$ are the mean stress and stress intensity on the interaction surface of this pair, respectively.

Detailed description of numerical implementations of Nikolaevsky's model as well as the fracture model within the formalism of the MCA method can be found elsewhere [34]. A numerical study was carried out with the use of the 2D sample, which models the microscale real contact area between two bodies of the same phase composition brought in sliding adhesionless contact (Fig. 12). The samples' surfaces had a roughness mean period of $0.06 \mu \mathrm{m}$ and mean asperity height of $0.03 \mu \mathrm{m}$. Periodic boundary conditions were established along the horizontal $x$-axis.

The contacting bodies were simulated by closepacked ensembles of equal-sized discrete $5 \times 10^{-4} \mathrm{~m}$ elements. Initially, all neighboring elements in each body were in an as-linked state. The subsurface layers were free of any defects. The top sample was fixed against displacement along the $x$-axis. A normal load $F_{y}$ was applied to the top sample along the $y$-axis, thus giving a contact stress of $200 \mathrm{MPa}$. The bottom of sample moved at $V_{x}=5 \mathrm{~m} / \mathrm{s}$ with respect to the fixed top one. Given that the bottom sample was fixed against displacement along the $y$-axis, the whole
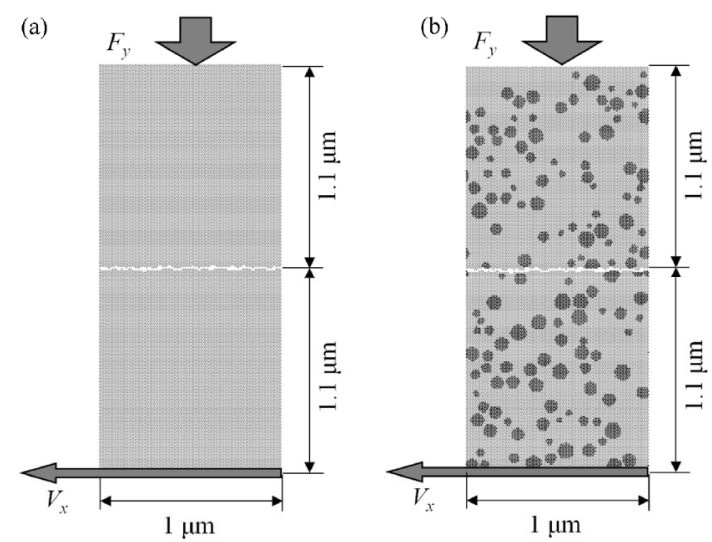

Fig. 12 Schematics of Y-TZP (a) and Y-TZP- $20 \% \mathrm{Al}_{2} \mathrm{O}_{3}$ (b) for the model samples and loading. 
system represented the sliding experiment when the fixed top sample slides over the surface of the moving bottom one.

Two types of friction couple were modeled: $\mathrm{Y}-\mathrm{TZP} /$ Y-TZP and Y-TZP-20\% $\% \mathrm{Al}_{2} \mathrm{O}_{3} / \mathrm{Y}-\mathrm{TZP}-20 \% \mathrm{Al}_{2} \mathrm{O}_{3}$. Their mechanical characteristics are shown in Table 1. Y-TZP and alumina were represented as elastic-plastic and elastic-brittle materials, respectively (Fig. 13).

The volume expansion effect of tetragonal-tomonoclinic transformation in Y-TZP was modeled using a dilatancy effect, as described above. The dilatancy coefficient was varied to reveal its effect on subsurface structure evolution in the numerical MCA experiment. The first stage was using zero dilatancy and internal friction coefficients, i.e., this was a nodilatancy associated plastic flow von Mises criterion model implying that the shear strength does not depend on the pressure and the inelastic volume does not change during inelastic deformation. All other material characteristics corresponded to those shown in Table 1. The results obtained at this stage show that the effective toughness of the Y-TZP ceramics was reduced, because numerous and deep cracks were

Table 1 Mechanical characteristics of the materials modeled.

\begin{tabular}{ccc}
\hline Characteristic & $\mathrm{ZrO}_{2}$ & $\mathrm{Al}_{2} \mathrm{O}_{3}$ \\
\hline Density $\rho\left(\mathrm{kg} / \mathrm{m}^{3}\right)$ & 5,700 & 3,984 \\
Young modulus $E(\mathrm{GPa})$ & 172 & 416 \\
Poisson ratio, $v$ & 0.3 & 0.3 \\
Elasticity limit $\sigma_{y}(\mathrm{MPa})$ & 980 & - \\
Internal friction coefficient, $\alpha$ & 0.57 & - \\
Dilatancy coefficient, $\Lambda$ & 0.1 & - \\
Compression strength $\sigma_{c}(\mathrm{MPa})$ & 1,400 & 1,400 \\
Tensile strength $\sigma_{t}(\mathrm{MPa})$ & 700 & 300 \\
\hline
\end{tabular}

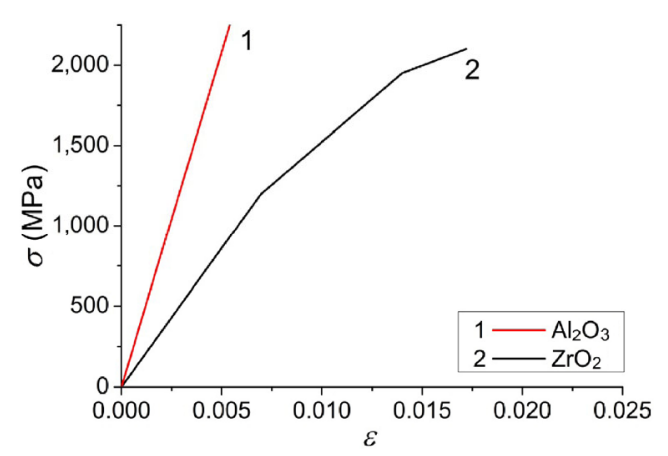

Fig. 13 Stress-strain diagrams for alumina (1) and Y-TZP (2). generated during sliding. These subsurface cracks could facilitate wear by fracture (Fig. 14(a)).

The results of the experiments with $\Lambda=0.1$ and $\Lambda=$ 0.2 show that the number of cracks, as well as their in-depth penetration, is reduced with $\Lambda$ (Figs. 14(b) and 14(c)). The integral parameters of submicron-sized sliding-induced cracks formed in the Y-TZP subsurface (Table 2) show that the crack characteristic length and penetration depth reduce by $25 \%-30 \%$ when the dilatancy coefficient grows from 0 to 0.2 . The rationale here is that the dilatancy of the material ahead of the crack tip might have created the constraint conditions for the crack growth and thus improved the fracture toughness by analogy with the effect of transformation plasticity in real Y-TZP. These crack parameters depend nonlinearly on the dilatancy coefficient $\Lambda$ with

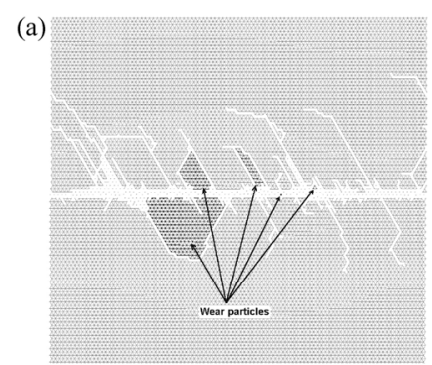

(c)
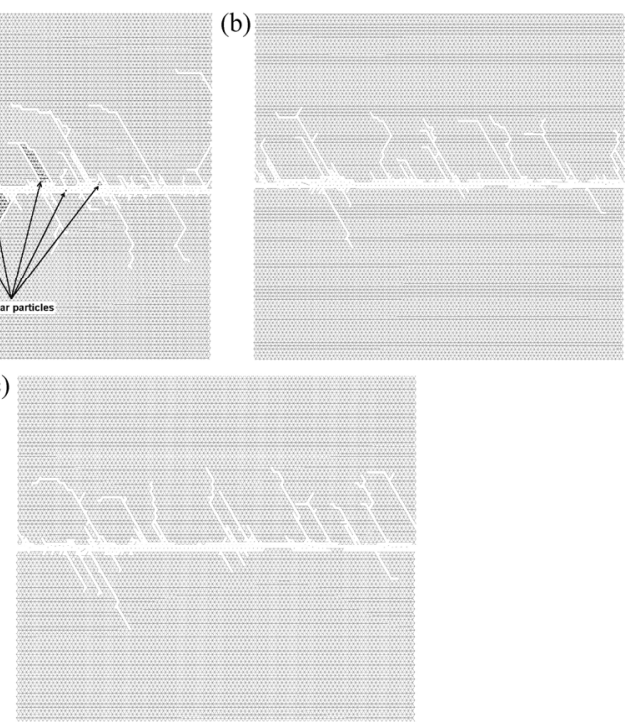

Fig. 14 Subsurface fracture in Y-TZP at dilatancy coefficient $\Lambda=0$ (a), $\Lambda=0.1$ (b), and $\Lambda=0.2$ (c).

Table 2 Parameters of $>0.05 \mu \mathrm{m}$ length subsurface cracks in the model samples of Y-TZP.

\begin{tabular}{cccc}
\hline Parameters & $\Lambda=0$ & $\Lambda=0.1$ & $\Lambda=0.2$ \\
\hline $\begin{array}{c}\text { Mean value of } \\
\text { crack length }^{1)}\end{array}$ & $0.26 \mu \mathrm{m}$ & $0.195 \mu \mathrm{m}$ & $0.18 \mu \mathrm{m}$ \\
$\begin{array}{c}\text { Mean in-depth penetration } \\
\text { of cracks }\end{array}$ & $0.19 \mu \mathrm{m}$ & $0.15 \mu \mathrm{m}$ & $0.14 \mu \mathrm{m}$ \\
\hline
\end{tabular}

Note: ${ }^{1)}$ Mean crack length has been determined as the total crack length-to-number ratio. ${ }^{2)}$ Mean in-depth penetration of cracks has been determined as a total crack penetration depth into the bulk of the material along the $y$-axis over the total crack number. Only $>0.05 \mu \mathrm{m}$ ( 5 automaton diameter) length cracks have been considered. 
a tendency to a plateau behavior at $\Lambda \sim 0.3$. Such a limitation of the submicron-crack-growth-suppressing mechanism by means of the phase-transformationinduced dilation is related to the opposing influence of the contact surface.

The column graph in Fig. 15(a) shows the wear particle size distributions generated by wear under conditions presented in Fig. 14. Each wear particle in the model contact zone was determined as an entity composed of only interlinked automata and isolated from the parent material by cracks (shown by arrows in Fig. 14(a)). The wear particle size in Fig. 15 is the so-called effective value, which is implied as a side length of a square wear particle composed of the same automaton number. The effective wear particle size was thus determined using the formula $D \sqrt{n}$, where $D$ is the automaton diameter, and $n$ is the number of automata belonging to the particle. Figure 15(a) shows that wear particles generated in the absence of the transformation-induced dilatancy $\Lambda=0$ (red columns) are at least one order of magnitude larger than those obtained with $\Lambda=0.1$ and $\Lambda=0.2$. The narrow and discrete wear particle size distributions in Fig. 15 were dictated by the limited model sample size as well as the finite size of the automaton, which is also the minimum wear particle size.

Even though the amount of large wear particles is two orders of magnitude less than that of fine ones composed of either one or few automata, their contribution to the volume/weight loss by wear is $50 \%$ higher. The results of modeling suggest that wear in the absence of dilatancy occurs by forming the wear particles of various size ranges with almost the same number of particles falling into each range. The dilatancy allows improving the fracture toughness by inducing the local compression stress within the geometrically constrained volumes, thus suppressing both the subsurface crack growth and generation of large wear particles.

Figure 15(a) shows that the increase in the dilatancy coefficient does reduce the wear particle size, which does not exceed the size of few automata at $\Lambda=0.2$ (see blue and magenta columns). These results suggest that the maximum size wear particles, as well as their contributions to total weight/volume losses, are in the reverse proportion to the local volume expansion degree that resulted from the phase transformation.
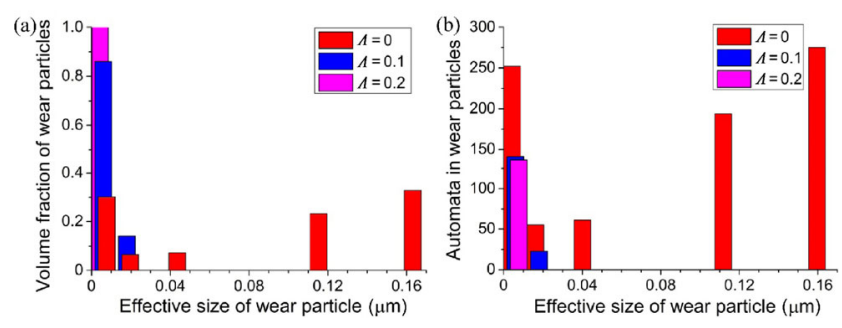

Fig. 15 Volume fractions (a) and mass contributions (b) of different size wear particles for three considered model ceramic materials with $\Lambda=0$ (red columns), $\Lambda=0.1$ (blue columns) and $\Lambda=0.2$ (magenta columns). Mass contributions are shown in arbitrary (automata amount) units.

When discussing the effect of this local volume expansion on wear, note that increasing the dilatancy coefficient results in manifold reduction of the wear particle total mass. The crossover from a classic "dilatancy-free" rheological model of the ceramics (von Mises plasticity) to the transformation-induced plasticity makes it possible to reduce the total wear losses by a factor of six (red and magenta columns in Fig. 15(b)).

Total mass losses by wear are assumed within this model framework as potential wear mass losses due to using the periodic boundary conditions, which do not imply any real mass losses.

The weight loss dependency on $\Lambda$ (Fig. 15(b)) shows a leveling upward tendency already at $\Lambda=0.2$. This may be explained by the above limitation of the crack growth suppression effect from the opposing influence of free wear particles of the contact surface. The results of modeling demonstrated the importance of transformation-induced dilatancy in modeling both the subsurface crack growth and wear.

Another result is that wear resistance improvement of Y-TZP ceramics is feasible by introducing alumina particles. A model Y-TZP- $20 \% \mathrm{Al}_{2} \mathrm{O}_{3}$ composite structure is given by Fig. 12(b). Alumina particles were homogeneously distributed in $1 \times 2.2 \mu \mathrm{m}^{2}$ area. The results of modeling show that the subsurface damaged layer has much lower thickness compared with that on Y-TZP ceramics (Fig. 16 and Fig. 14(c)). Both the amount and length of the wear-generated subsurface cracks, as well as the total mass of the wear particles, are also several times lower. Crack propagation is retarded near alumina particles, so that they are redirected along the particle-matrix interface. This is especially the case in the constraint interparticle space 


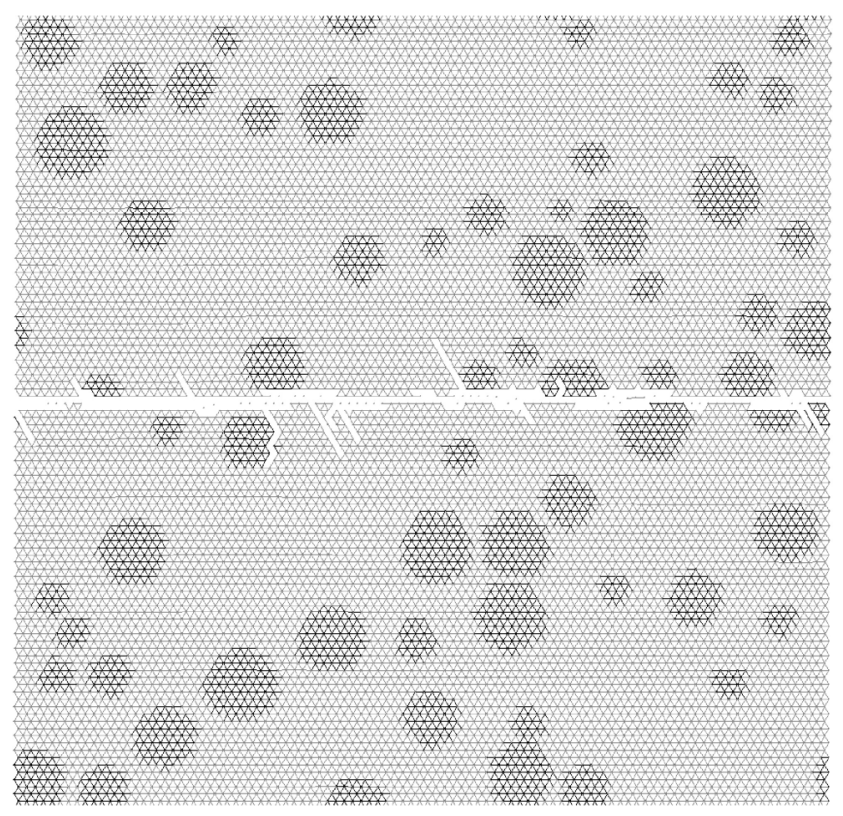

Fig. 16 Subsurface fracture on Y-TZP- $20 \% \mathrm{Al}_{2} \mathrm{O}_{3}$ at dilatancy coefficient $\Lambda=0.2$.

when two alumina particles are close to each other; therefore, the dilatancy exerts compression stress between the particles. When this interparticle distance is greater, the cracks may propagate deeper inside the ceramics long after less compression stress is generated.

When discussing the results of simulation, it necessary to mention that quantitative values of the parameters of subsurface cracks and wear particles were obtained using the particular (fixed) size of movable cellular automata. As shown in Ref. [37], when applying a local mesh-independent fracture criterion, for example, the fracture criterion (3)-the magnitudes of the "ultimate" local stresses at which asperities detach from the surface or subsurface cracks nucleate are automaton-size-dependent. Therefore, the automaton size determines the quantitative characteristics of the damage and wear of the surface layer. A promising way to eliminate this technical dependence is to apply the mesh-dependent (scaled) formulation of fracture criterion, which was first introduced and verified for adhesive contacts [38, 39] and described for the particular case of the discreteelement method [37]. Use of the mesh-dependent criterion should provide more-accurate estimates of the wear characteristics, while the above-discussed regularities of the influence of coefficient $\Lambda$ remain the same.
The results of numerical simulation using the MCA method and dilatant plasticity model support the conclusions made on the basis of experimental data. The dilatancy approach to modeling the wear behavior of transformation-induced plasticity ceramics therefore deserves attention and may be successfully applied.

\section{Discussion}

The LTD is inherent in almost all zirconia-based highfracture-toughness ceramic materials that experience tetragonal-to-monoclinic transformation under mechanical loading, including sliding friction. It was shown earlier that wear in these ceramics is fully determined by a phase-transformation-dependent mechanism. These materials, however, are used in numerous sliding friction couples, including those working in high-humidity conditions where LTD is an especially fast-occurring process. The LTD may be inhibited by tetragonal grain refining or adding the reinforcement alumina grains, which exert internal residual stress in the composite because of thermal expansion. Therefore, there is interest in studying the LTD-aged samples' behavior under sliding conditions.

In this work, the T-TZP-based LTD-aged samples were intentionally destabilized by storing them for 20 years in air under room temperatures, so that the amount of a monoclinic phase in Y-TZP was $60 \mathrm{vol} \%$. Despite that high monoclinic-phase content, the sliding-friction-induced tetragonal-to-monoclinic transformation occurred both in Y-TZP and Y-TZP- $\mathrm{Al}_{2} \mathrm{O}_{3}$ materials during wear. The transformation intensity depended, however, on a specific sliding speed and load combination, as well as the ceramics type.

The results of wear experiments show that a Y-TZP- $\mathrm{Al}_{2} \mathrm{O}_{3} /$ steel couple had lower friction coefficients, lower AE energy, and higher median frequency values, as well as less damaged worn surfaces compared with those of Y-TZP/steel ones. On the basis of these results, as well as on the literature sources, these distinctions arise from differences in acting wear mechanisms, which are somehow connected with the transformation toughening.

\section{$5.1 \quad \mathrm{Y}-\mathrm{TZP}$}

It was noted above that friction-generated heat has its 
effect on the worn surface monoclinic phase so that inverse monoclinic-to-tetragonal transformation can occur almost simultaneously with the direct one. Also, mechanical fragmentation and grain subdivision of the ceramic grains during sliding will inevitably facilitate the inverse transformation. The result of these processes will be the formation of the XRD textures, which are detected by tetragonal and monoclinic peak $\mathrm{I}_{002} / \mathrm{I}_{200}$ intensity inversions.

Increasing the sliding speed above $1 \mathrm{~m} / \mathrm{s}$ results in heating the ceramic subsurface layer to temperatures that partially inhibit the direct stress-induced transformation and transformation-induced plasticity, thus causing catastrophic thermomechanical deterioration of the low-heat-conductivity zirconia ceramics.

The LTD-aged samples used in this work already had a 60 vol. \% monoclinic phase in the subsurface layer; therefore, there were numerous defects.

Sliding at $0.5 \mathrm{~m} / \mathrm{s}$ may easily peel this defect layer off the sample and, thus, form a wear debris layer, which is subjected to further deformation and heating. These particles may then partially experience inverse transformation and become tetragonal-phase ones. Simultaneously, tetragonal bulk grains experience strain-induced direct transformation and also form wear particles, which then may be heated at the real contact areas and become tetragonal ones again. Finally, we may have a tribological layer consisting of fine ceramic particles where both direct and inverse transformation dynamically occur during sliding and forming the XRD textures.

The vibration acceleration RMS changed in time in accordance with the friction coefficient, so that steady-mode friction with only background RMS values was observed for a long period until the formation of wide peaks. Such a steady-mode dynamics may be explained by the strain-induced for the material at low sliding speed. High-amplitude vibrations appeared closer to the end of the test and may be related to the loss of plasticity because of friction heating. For sliding at $0.5 \mathrm{~m} / \mathrm{s}$ and $26 \mathrm{~N}$, vibration acceleration RMS stays minimal only for a short period of time because of faster friction heating at that high load.

Sliding at $1 \mathrm{~m} / \mathrm{s}$ and $13 \mathrm{~N}$ shifts the equilibrium to the inverse transformation region when there is no structural adaptability mechanism in the form of direct transformation mechanisms. The result is catastrophic deterioration of the worn surface by cracking and detaching of large wear particles. Intense cracking definitely causes intense high-amplitude AE signals with low median frequency and high AE energy, whereas transformation-induced plasticity must give high median frequency and low AE energy because of the arresting of the subsurface crack propagation. The vibration acceleration RMS shows peaks from the beginning of the sliding, thus being in accordance with the friction coefficient and friction heat generated. The same could be true for sliding at $1 \mathrm{~m} / \mathrm{s}$ and $26 \mathrm{~N}$.

Numerical studies of wear in Y-TZP support the above-discussed experimental data, showing intense crack development in the material as a result of the transformation dilatancy effect.

\section{$5.2 \mathrm{Y}-\mathrm{TZP}-\mathrm{Al}_{2} \mathrm{O}_{3}$}

The specificity of wear and friction in the Y-TZP$\mathrm{Al}_{2} \mathrm{O}_{3} /$ steel couple may have several aspects. The first is that high-modulus reinforcement alumina particles are distributed among the zirconia ones, giving them high-thermomechanical stability and less sensitivity to high temperatures [40]. Such a reinforcement makes it possible to attain higher fracture toughness, even after full high-temperature loss of transformation toughening because of crack propagation deflection on the reinforcement particles.

The second aspect is that alumina particles create some constraint conditions to avoid excess straininduced plasticity and microcracking, thus improving the effect of transformation toughening and arresting the subsurface crack propagation in sliding [40]. Relatively high heat conductivity of alumina particles, i.e., $40 \mathrm{~W} /(\mathrm{m} \cdot \mathrm{K})$ at $25^{\circ} \mathrm{C}$ as compared with $2 \mathrm{~W} /(\mathrm{m} \cdot \mathrm{K})$ of $\mathrm{ZrO}_{2}-\mathrm{Y}_{2} \mathrm{O}_{3}$ in the temperature range $100-1,400{ }^{\circ} \mathrm{C}$ is the third aspect contributing to friction on Y-TZP- $\mathrm{Al}_{2} \mathrm{O}_{3}$. Therefore, Y-TZP- $\mathrm{Al}_{2} \mathrm{O}_{3}$ has better heat removal conditions in sliding and better thermodynamic conditions for strain-induced transformation toughening. These three aspects contribute to better wear resistance of $\mathrm{Y}-\mathrm{TZP}-\mathrm{Al}_{2} \mathrm{O}_{3}$ as compared to $\mathrm{Y}-\mathrm{TZP}$, and this is supported also by the fact that the Y-TZP$\mathrm{Al}_{2} \mathrm{O}_{3}$ tetragonal $\mathrm{I}_{(002)} / \mathrm{I}_{(200)}$ and monoclinic $\mathrm{I}_{(11-1)} / \mathrm{I}_{(111)}$ ratios are higher than those of Y-TZP. The Y-TZP$\mathrm{Al}_{2} \mathrm{O}_{3}$ may have experienced more-intense reversible 
transformation.

That effective reversible transformation in Y-TZP$\mathrm{Al}_{2} \mathrm{O}_{3}$ provides efficient stress relaxation on the worn surface and reduces surface deterioration. Relatively milder wear in the $\mathrm{Y}-\mathrm{TZP}-\mathrm{Al}_{2} \mathrm{O}_{3} /$ steel couple is accompanied by lower AE signal energy and higher median frequency.

Vertical and horizontal vibrations changed in time in accordance with friction coefficient except for those obtained in sliding at $1 \mathrm{~m} / \mathrm{s}$ and $26 \mathrm{~N}$. Also, there is steady stage of the vibration acceleration RMS dependence for $0.5 \mathrm{~m} / \mathrm{s}$ and $13 \mathrm{~N}$, which could be related to the above-discussed specificity of the wear and phase transformation in this metal. Also, highRMS peaks might be caused by the indenting of the counter body by free alumina grains, which are harder than those of zirconia and do experience strain-induced transformation. Thus, wear debris should be composed of large alumina grains and smaller zirconia ones that still may be capable of strain-induced transformation for the reasons stated above.

Even though the MCA modeling could not reproduce any inverse transformation effects, it showed that the subsurface fracture zone thickness for $\mathrm{Y}-\mathrm{ZP}-\mathrm{Al}_{2} \mathrm{O}_{3}$ was less than that of Y-TZP.

\section{Conclusion}

Acoustic emission mean characteristics, such as median frequency and AE energy, were found to be a material response to sliding speed and load combinations, taking into account the cumulative effect of competing sliding process factors, such as strain and temperature, on the phase transformation in LTDaged Y-TZP and Y-TZP- $\mathrm{Al}_{2} \mathrm{O}_{3}$. Hybrid Y-TZP- $\mathrm{Al}_{2} \mathrm{O}_{3} /$ steel sliding showed better tribological characteristics than those of Y-TZP because of their structure. These results are supported by numerical-modeling ones that showed that Y-TZP strain-induced transformation dilatancy in a constraint shear condition within the contact spot retards the subsurface crack nucleation and crack arresting at a depth lower than that without taking account of the dilatancy. Similar results have been obtained for the Y-TZP- $\mathrm{Al}_{2} \mathrm{O}_{3}$ composite. Subsurface nucleates predominantly on the $\mathrm{Y}-\mathrm{TZP} / \mathrm{Al}_{2} \mathrm{O}_{3}$ interfaces, which serve as stress concentrators and then are arrested in the matrix by transformationinduced dilation constraint bulk stresses.

The worn surfaces of both materials showed the presence of inverse peak intensity ratios, i.e., the traces of reversible transformation. Inverse monoclinic-totetragonal transformation occurred in the case of higher friction heating, which also caused AE energy growth because of the loss of subsurface crack-arresting capability and inhibition of direct strain-induced transformation.

As shown, there is a strong correlation between AE signal parameters and XRD texturing of the monoclinic and tetragonal phases. Increasing the textured peak ratio leads to a decrease in AE signal energy and friction coefficient. The LTD-aged samples contained the same amount of monoclinic phase in their Y-TZP components. Nevertheless, the monoclinic phase $\mathrm{I}(11-1) / \mathrm{I}(111)$ ratio increased after sliding with the AE signal median frequency and decreased with the AE signal energy and friction coefficient. Therefore, AE may be an effective method for in-situ monitoring of the subsurface wear of materials experiencing both direct and inverse transformation.

\section{Acknowledgments}

The work was financially supported by the Russian Federation via the Ministry of Education and Science of the Russian Federation (Agreement No. 14.607.21.0186, project identifier RFMEFI60717X0186).

Open Access: The articles published in this journal are distributed under the terms of the Creative Commons Attribution 4.0 International License (http:// creativecommons.org/licenses/by/4.0/), which permits unrestricted use, distribution, and reproduction in any medium, provided you give appropriate credit to the original author(s) and the source, provide a link to the Creative Commons license, and indicate if changes were made.

\section{References}

[1] Turon-Vinas M, Anglada M. Strength and fracture toughness of zirconia dental ceramics. Dental Mater 34(3): 365-375 (2018) 
[2] Deville S, Gremillard L, Chevalier J, Fantozzi G. A critical comparison of methods for the determination of the aging sensitivity in biomedical grade yttria-stabilized zirconia. $J$ Biomed Mater Res Part B Appl Biomater 72B(2): 239-245 (2005)

[3] Reveron H, Fornabaio M, Palmero P, Fürderer T, Adolfsson E, Lughi V, Bonifacio A, Sergo V, Montanaro L, Chevalier J. Towards long lasting zirconia-based composites for dental implants: Transformation induced plasticity and its consequence on ceramic reliability. Acta Biomater 48: 423-432 (2017)

[4] Fischer T E, Anderson M P, Jahanmir S. Influence of fracture toughness on the wear resistance of yttria-doped zirconium oxide. J Am Ceram Soc 72(2): 252-257 (1989)

[5] Lee S W, Hsu S M, Shen M C. Ceramic wear maps: Zirconia. J Am Ceram Soc 76(8): 1937-1947 (1993)

[6] Swain M V, Hannink R H J. Metastability of the martensitic transformation in a $12 \mathrm{~mol} \%$ ceria-zirconia alloy: II, grinding studies. J Am Ceram Soc 72(8): 1358-1364 (1989)

[7] Korolev P V, Savchenko N L, Kul'kov S N. Texture formation on the friction surface in transformation-toughened ceramics. Tech Phys Lett 30(1): 12-14 (2004)

[8] Becker P C, Libsch T A, Rhee S K. Wear mechanisms of toughened zirconias. In Proceedings of the 9th Annual Conference on Composites and Advanced Ceramic Materials. The American Ceramic Society, 1985: 1040-1058

[9] Savchenko N L, Kul'kov S N. Friction and wear of Y-TZP and $\mathrm{Y}-\mathrm{TZP}-\mathrm{Al}_{2} \mathrm{O}_{3}$ ceramics in high-speed sliding on steel. $J$ Frict Wear 30(6): 444-448 (2009)

[10] Wu K G, Choe C Y, Lee S M, Yoo J A, Hyun C Y, Hong D $\mathrm{P}$, Byeon J W. Real-time monitoring of degradation of zirconia ceramic by acoustic emission. Appl Mech Mater 433-435: 816-820 (2013)

[11] Hua Z K, Fan Y W, Jin Z M. A biotribo-acoustic testing method for ceramic orthopaedic biomaterials. Tribol Int 71: $1-6(2014)$

[12] Taylor S, Manley M T, Sutton K. The role of stripe wear in causing acoustic emissions from alumina ceramic-on-ceramic bearings. J Arthroplasty 22(S7): 47-51 (2007)

[13] Wang L, Wood R J K. Acoustic emissions from lubricated hybrid contacts. Tribol Int 42(11-12): 1629-1637 (2009)

[14] Filippov A V, Rubtsov V E, Tarasov S Y. Acoustic emission study of surface deterioration in tribocontacting. Appl Acoust 117: 106-112 (2017)

[15] Filippov A V, Nikonov A Y, Rubtsov V E, Dmitriev A I, Tarasov S Y. Vibration and acoustic emission monitoring the stability of peakless tool turning: Experiment and modeling. J Mater Process Technol 246: 224-234 (2017).

[16] Filippov A V, Tarasov S Y, Fortuna S V, Podgornykh O A,
Shamarin N N, Rubtsov V E. Microstructural, mechanical and acoustic emission-assisted wear characterization of equal channel angular pressed (ECAP) low stacking fault energy brass. Tribol Int 123: 273-285 (2018)

[17] Rubtsov V E, Kolubaev E A, Kolubaev A V, Popov V L. Using acoustic emission for the analysis of wear processes during sliding friction. Tech Phys Lett 39(2): 223-225 (2013)

[18] McBride S L, Boness R J, Sobczyk M, Viner M R. Acoustics emission from lubricated and rubbing surfaces. J Acoust Emiss 8(1-2): 192-196 (1989)

[19] Clarke D R, Arora A. Acoustic emission characterization of the tetragonal-monoclinic phase transformation in zirconia. In Advances in Ceramics, Vol. 12, Science and Technology of Zirconia II. Claussen N, Heuer A H, Ruhle M, Eds. Columbus, OH: American Ceramic Society, 1984.

[20] Lankford J. Plastic deformation of partially stabilized zirconia. J Am Ceram Soc 66(11): c212-c213 (1983)

[21] Drozdov A V, Galenko V O, Gogotsi G A, Swain M V. Acoustic emission during micro- and macrocrack growth in Mg-PSZ. J Am Ceram Soc 74(8): 1922-1927 (1991)

[22] Chu L, Ren H, Ning J. Damage and Toughening Analysis of Ceramics by AE Location Method//G. Shen et al. (eds.), Advances in Acoustic Emission Technology: Proceedings of the World Conference on Acoustic Emission-2013, Springer Proceedings in Physics 158: 313-321

[23] Jacobus K, Sehitoglu H, Balzer M. Effect of stress state on the stress-induced martensitic transformation in polycrystalline Ni-Ti Alloy. Metall Mater Trans A 27(10): 3066-3073 (1996)

[24] Stam G T M, Van Der Giessen E, Meijers P. Effect of transformation-induced shear strains on crack growth in zirconia-containing ceramics. Int J Solids Struct 31(14): 1923-1948 (1994)

[25] Sun Q P, Hwang K C. Micromechanics modelling for the constitutive behavior of polycrystalline shape memory alloys-I. Derivation of general relations. J Mech Phys Solids 41(1): 1-17 (1993)

[26] Patoor E, Lagoudas D C, Entchev P B, Brinson L C, Gao X J. Shape memory alloys, Part I: General properties and modeling of single crystals. Mech Mater 38(5-6): 391-429 (2006)

[27] Lagoudas D C, Entchev P B, Popov P, Patoor E, Brinson L C, Gao X J. Shape memory alloys, Part II: Modeling of polycrystals. Mech Mater 38(5-6): 430-462 (2006)

[28] Lankford J, Page R A, Rabenberg L. Deformation mechanisms in yttria-stabilized zirconia. J Mater Sci 23(11): 4144-4156 (1988)

[29] Nikolaevsky V N. Geomechanics and Fluidodynamics: with Applications to Reservoir Engineering. Dordrecht, Boston: Kluwer Academic, 1996 
[30] Stefanov Y P, Chertov M A, Aidagulov G R, Myasnikov A V. Dynamics of inelastic deformation of porous rocks and formation of localized compaction zones studied by numerical modeling. J Mech Phys Solids 59(11): 2323-2340 (2011)

[31] Eremin M O. Numerical simulation of fracture of $\mathrm{ZrO}_{2}-\mathrm{Al}_{2} \mathrm{O}_{3}$ ceramic composites. Phys Mesomech 19(4): 452-458 (2016)

[32] Psakhie S, Shilko E V, Smolin A, Astafurov S, Ovcharenko $\mathrm{V}$ E. Development of a formalism of movable cellular automaton method for numerical modeling of fracture of heterogeneous elastic-plastic materials. Fract Struct Integr 7(24): 26-59 (2013)

[33] Shilko E V, Psakhie S G, Schmauder S, Popov V L, Astafurov S V, Smolin A Y. Overcoming the limitations of distinct element method for multiscale modeling of materials with multimodal internal structure. Comput Mater Sci 102: 267-285 (2015)

[34] Psakhie S G, Shilko E V, Grigoriev A S, Astafurov S V, Dimaki A V, Smolin A Y. A mathematical model of particleparticle interaction for discrete element based modeling of deformation and fracture of heterogeneous elastic-plastic materials. Eng Fract Mech 130: 96-115 (2014)

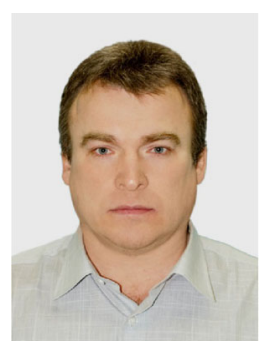

Nikolai L SAVCHENKO. He received his MS degree in metallurgical engineer at the Tomsk Polytechnic Institute (USSR) in 1987, $\mathrm{PhD}$ degree in physics in 1995 and Dr Sci degree in materials in 2015 at the Institute of Strength Physics and

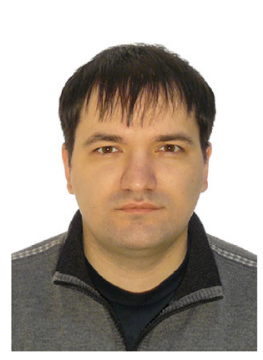

Andrey V FILIPPOV. He received his $\mathrm{PhD}$ degree at the Institute of Strength Physics and Materials Science SB RAS in 2015. He joined the Tomsk Polytechnic University (TPU), Department of at Materials Machining Technologies in 2011. His current positions are a researcher at
[35] Dmitriev A I, Österle W, Wetzel B, Zhang G. Mesoscale modeling of the mechanical and tribological behavior of a polymer matrix composite based on epoxy and 6 vol.\% silica nanoparticles. Comput Mater Sci 110: 204-214 (2015)

[36] Alejano L R, Bobet A. Drucker-prager criterion. Rock Mech Rock Eng 45(6): 995-999 (2012)

[37] Dimaki A, Shilko E V, Psakhie S, Popov V L. Simulation of fracture using a mesh-dependent fracture criterion in the discrete element method. Facta Univ Ser Mech Eng 16(1): 41-50 (2018)

[38] Pohrt R, Popov V L. Adhesive contact simulation of elastic solids using local mesh-dependent detachment criterion in Boundary Elements Method. Facta Univ Ser Mech Eng 13(1): 3-10 (2015)

[39] Popov V L, Pohrt R, Li Q. Strength of adhesive contacts: Influence of contact geometry and material gradients. Friction 5(3): 308-325 (2017)

[40] Kelly J R, Denry I. Stabilized zirconia as a structural ceramic: An overview. Dent Mater 24(3): 289-298 (2008)

Materials Science SB RAS in Tomsk (Russia). His current position is the leading researcher of Laboratory for Quality Control in Materials and Structures in the Institute of Strength Physics and Materials Science SB RAS. His research focuses on CMC and MMC tribology, interfacial phenomena, surface characterization, etc.

the Institute of Strength Physics and Materials Science SB RAS, Laboratory of Surface Hardening Physics, and an associate professor at Tomsk Polytechnic University. His research areas cover structural evolution of fine- and ultrafine-grained materials under severe subsurface deformation by friction and cutting with detailed analysis of vibration and acoustic emission phenomena. 


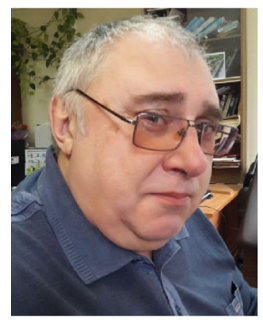

Sergei Yu TARASOV. He received his PhD and Dr. Sci. degrees at the Institute of Strength Physics and Materials Science SB RAS in 1994 and 2009, respectively. His current position is a leading researcher at the Institute of Strength Physics

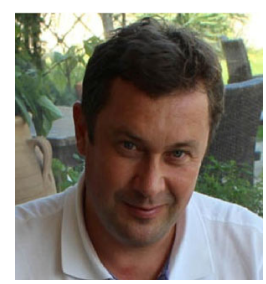

Andrey I DMITRIEV. He received his $\mathrm{PhD}$ and Dr. Sci. degrees in condensed mater physics at the Institute of Strength Physics and Materials Science (ISPMS) SB RAS in 1997 and 2006, respectively. He joined the Tomsk State University (TSU), Department

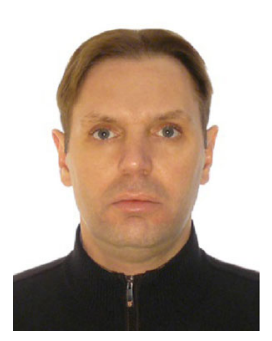

Evgeny V SHILKO. He received his MS degree in solid state physics in 1995 from Tomsk State University, Russia. After that he obtained his $\mathrm{PhD}$ and Dr Sci degrees in deformable solid mechanics at the Institute of Strength Physics and Materials Science SB RAS (ISPMS SB RAS), Tomsk,

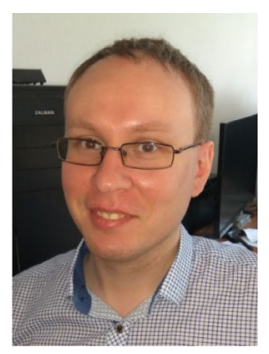

Aleksandr S GRIGORIEV. He received his MS degree in applied mechanics in 2012 from Tomsk State University, Russia. He joined the Laboratory of Computer-Aided Design of Materials at the Institute of Strength Physics and Materials and Materials Science SB RAS. He joined the Tomsk Polytechnic University in 2013 as a professor. His research areas cover all aspects of material structural evolution materials under severe subsurface deformation by friction with special attention given to friction stir processing of iron- and aluminum-base materials.

of Metal Physics in 2005. His current positions are a principal researcher at ISPMS SB RAS, Laboratory of Computer-Aided Design of Materials, and a professor at Tomsk State University. His research areas cover computer modeling in tribology and nanotribology using numerical methods of various scales on the basis of discrete approach.

Russia, in 1998 and 2007, respectively. He joined the Laboratory of Computer-Aided Design of Materials at ISPMS SB RAS from 1998. His current positions are a principal researcher of the laboratory and a professor at the Physical Faculty at Tomsk State University. His research areas cover computer modeling of fracture at different scales, mechanics of fluid-saturated solids and contact mechanics.

Science SB RAS (ISPMS SB RAS), Tomsk, Russia, from 2012. His current position is a junior researcher of the laboratory. His research interests include computer modeling in the fields of dynamic mechanical behavior of solids, rock mechanics and contact interaction of solids. 